
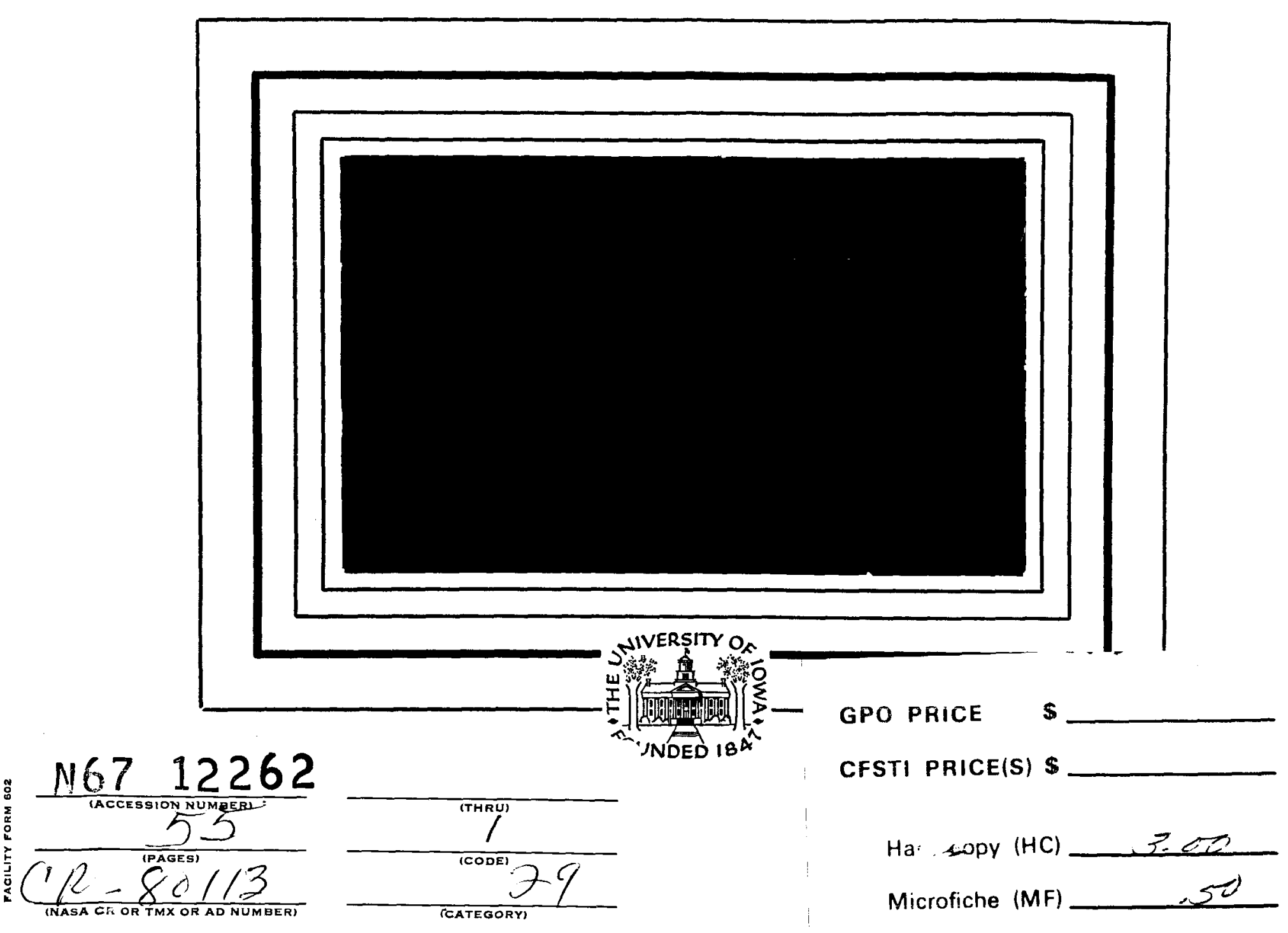
$\because 852 \quad 2+; 85$

This work was supported in part by the office of Naval Research under Coritract No. Nonr-1509:06)

Department of Physics and Astronomy THE UNIVERSITY OF IOWA

Iowa City, Iowa 
$\mathrm{U}$. of Iowa $66-48$

\title{
SEVERAL OBSERVATIONS OF LOW-ENERGY \\ PROTONS AND ELECTRONS IN THE \\ EARTH'S MAGNETOSPHERE \\ WITH OGO $3 *$
}

by

I. A. Frank

\author{
Department of Physics and Astronomy \\ University of Iowa \\ Iowa City, Iowa
}

November 1966

* Research supported in part by the National Aeronautics and Space Administration under Grant NsG-233-62 and Contract NAS5-2054 and by the Office of Naval Research under Contract Nonr-1509(06).

Distribution of this document is unlimited. 


\title{
Abstract
}$$
122<2
$$

Simultaneous observations of proton (190 eV $\leq \mathrm{E} \leq 48 \mathrm{keV}$ )
\end{abstract} and electron (170 eV $\leq \mathrm{E} \leq 46 \mathrm{keV}$ ) differential energy spectrums during segments of three outbound traversals of OGO 3 through the magnetosphere for the period 11-15 June 1966/ on I-shells 3.3 to 16 are presented. Proton intensities at $L=4$ on 15 June 1966 were $8 \times 10^{5}\left(\mathrm{~cm}^{2} \text {-sec-sr }\right)^{-1}(330 \leq \mathrm{E} \leq 530 \mathrm{eV})$, $\lesssim 1.5 \times 10^{6}\left(\mathrm{~cm}^{2}-\mathrm{sec}-\mathrm{sr}\right)^{-1}(4.7 \leq \mathrm{E} \leq 7.6 \mathrm{keV})$ and $\lesssim 10^{6}$ $\left(\mathrm{cm}^{2}-\mathrm{sec}-\mathrm{sr}\right)^{-1}(16 \leq \mathrm{E} \leq 26 \mathrm{keV})$ and at $\mathrm{L}=7.5$ were $\leq 5 \times 10^{4}\left(\mathrm{~cm}^{2}-\mathrm{sec}-\mathrm{sr}\right)^{-1}(330 \leq \mathrm{E} \leq 530 \mathrm{eV}), 4 \times 10^{6}$ $\left(\mathrm{cm}^{2}-\mathrm{sec}-\mathrm{sr}\right)^{-1}(4.7 \leq \mathrm{E} \leq 7.6 \mathrm{keV})$ and $6 \times 10^{6}\left(\mathrm{~cm}^{2}-\mathrm{sec}-\mathrm{sr}\right)^{-1}$ (16 $\leq \mathrm{E} \leq 26 \mathrm{keV}$ ) with local pitch angles $78^{\circ}\left( \pm 4^{\circ}\right)$ and at a geomagnetic latitude $23^{\circ}\left( \pm 1^{\circ}\right)$. Peak intensities of protons $(30 \leq \mathrm{E} \leq 48 \mathrm{keV})$ were observed at $\mathrm{L} \simeq 7.0$. A preliminary order-of-magnitude estimate of the total energy of trapped protons/ (190 eV $\leq E \leq 48 \mathrm{keV}$ ) within the earth's magnetosphere is $5 \times 10^{21}$ ergs and the estimated contribution from this lowenergy proton distribution to the quiet-time terrestrial ring current field at the earth's surface is $\sim-10 \%$. A transient, narrow peak of relatively high low-energy proton and electron

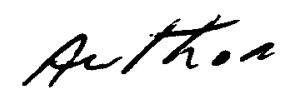


intensities within the energy range $\sim 300 \mathrm{eV}$ to $2 \mathrm{keV}$ at $\mathrm{I} \simeq 4$ with width $\Delta I \sim 1$ is also observed. Typical characteristics of proton and electron intensity 'spikes' at peak intensities in the late evening sector of the earth's magnetic tail are (a) approximately equal proton (190 eV $\leq \mathrm{E} \leq 48 \mathrm{keV}$ ) and electron ( 170 eV $\leq \mathrm{E} \leq 46 \mathrm{keV}$ ) energy densities, $\sim 10^{-9}$ $\operatorname{erg}(\mathrm{cm})^{-3}$ each, (b) approximately equal proton and electron densities over the above energy range, $\sim 1(\mathrm{~cm})^{-3}$ each, and (c) largely dissimilar differential energy spectrums, proton spectrums with intensity peaks noncoincident in energy with those of the electron intensity peaks and significantly broader (harder) in the high-energy tail $(E \gtrsim 3 \mathrm{keV}$ ) than the relatively steep (soft) electron spectrums in this energy range. 


\section{Introduction}

Observations of low-energy protons and electrons over the energy range extending from approximately $100 \mathrm{eV}$ to $100 \mathrm{keV}$ within the earth's magnetosphere are essential toward the understanding of many magnetospheric phenomena including the terrestrial ring currents, the acceleration processes responsible for the corpuscular radiation precipitated into the auroral regions, the plasmas within the earth's magnetic tail, and the sources of higher energy protons and electrons populating the earth's radiation zones. This initial survey of low-energy electrons and protons over geocentric radial distances ranging from $3 \mathrm{R}_{\mathrm{E}}$ to $15 R_{E}\left(R_{E}\right.$, earth radius) with measurements obtained with a sensitive electrostatic analyzer device borne on the earthsatellite OGO 3 is intended to provide an introduction to several of the characteristics of the spatial distributions of electrons and protons over an energy range $200 \mathrm{eV}$ to $50 \mathrm{keV}$ within the earth's magnetosphere near the magnetic equatorial plane. The search for the terrestrial ring currents by in situ measurements is continued in the present investigation [ cf Davis, 1965; Hoffman and Bracken, 1965; Cahill, 1966; Frank, 1966a] during a 
period of relative magnetic quiescence, and several features of the charged particle distributions at the boundary of durable trapping of charged particles by the geomagnetic field at geocentric radial distances approximately $8 \mathrm{R}_{\mathrm{E}}$ in the evening sector of the earth's magnetosphere are clarified. Simuitaneous odservaliuss of the aifferential cncrgy spectrums of electrons and protons, separately, over the aforementioned energy range are presented herein for regions in the earth's magnetic tail and deep within the radiation zones and will be important in delineating prominent acceleration mechanisms providing 'Iocal' acceleration of charged particles within the earth's magnetosphere and its environs. The spirit of the following discussion is directed toward an exploratory examination of low-energy proton and electron intensities in the earth's magnetosphere with unique and discriminative observations. 


\section{Description of Apparatus}

OGO 3 (1966-49A) was launched at 02:48 U.T. on 7 June 1966 into a highly eccentric orbit with initial apogee $128,500 \mathrm{~km}$ and perigee $6,700 \mathrm{~km}$ geocentric radial distances, inclination $31^{\circ}$ and period 48.6 hours. At launch the local time of the direction from the center of earth to spacecraft apogee position was $\sim 22: 00$. A composite system of reaction wheels and gas jets provided a predetermined, monitored orientation of the various spacecraft coordinates with respect to the directions from the satellite to earth and the sun and with respect to the orbital plane. The University of Iowa instrumentation includes four cylindrical-plate electrostatic analyzers to select charged particle energy and continuous channel multipliers (Bendix 'channeltrons') as charged particle detectors. Each of the two pairs of electrostatic analyzers provides simultaneous measurements of the intensities of protons and electrons, separately, within the same energy bandpasses over an energy range extending from approximately $100 \mathrm{eV}$ to $50,000 \mathrm{eV}$. The directions of the fields of view of these two pairs of electrostatic analyzers, designated as LEPEDEA's ' $A$ ' and ' $B$ ', are 
orthogonal and are directed parallel to spacecraft body Cartesian axes, + Z (toward earth during normal spacecraft operations) and $+\mathrm{Y}$, respectively. Two EON type 213 Geiger-Mueller tubes (1.2 $\mathrm{mg}(\mathrm{cm})^{-2}$ mica windows) were positioned in the instrument package such that the directions of their collimated fields of vicw were parellel to those of the electrostatic analyzer pairs. More detailed descriptions of the instrumentation have been given previously by Frank [1966b]. The energy bandpasses for the proton and electron channels of LEPEDEA ' $B$ ' are summarized in Table I (protons) and Table II (electrons). Observations with the second pair of electrostatic analyzers, LEPEDEA 'A', will be reported in a forthcoming survey of the angular distributions of low-energy protons and electrons. 
TABLE I

OGO 3 LEPEDEA PROTON CHANNELS ' $\mathrm{B}$ '

ENERGY BANDPASSES

\begin{tabular}{|cl|}
\hline Proton Channel & Energy Bandpass* \\
\hline $3 \mathrm{pB}$ & $90-150 \mathrm{eV}$ \\
$4 \mathrm{pB}$ & $190-320 \mathrm{eV}$ \\
$5 \mathrm{pB}$ & $330-530 \mathrm{eV}$ \\
$6 \mathrm{pB}$ & $450-720 \mathrm{eV}$ \\
\hline $7 \mathrm{pB}$ & $690-1100 \mathrm{eV}$ \\
$8 \mathrm{pB}$ & $1.1-1.8 \mathrm{keV}$ \\
$9 \mathrm{pB}$ & $1.8-2.9 \mathrm{keV}$ \\
$10 \mathrm{pF}$ & $3.3-5.3 \mathrm{keV}$ \\
\hline $11 \mathrm{pB}$ & $4.7-7.6 \mathrm{keV}$ \\
$12 \mathrm{pB}$ & $6.7-11 \mathrm{keV}$ \\
$13 \mathrm{pB}$ & $11-18 \mathrm{keV}$ \\
$14 \mathrm{pB}$ & $16-26 \mathrm{keV}$ \\
\hline $15 \mathrm{pB}$ & $30-48 \mathrm{keV}$ \\
\hline
\end{tabular}

*Analyzer constant is $7.6 \mathrm{eV}$ (volt) ${ }^{-1}$ 
TABLE II

OGO 3 LEPEDEA ELECTRON CHANNELS ' $\mathrm{B}$ '

ENERGY BANDPASSES*

\begin{tabular}{|cc|}
\hline Electron Channel & Energy Bandpass** \\
\hline $3 \mathrm{eB}$ & $80-140 \mathrm{eV}$ \\
$4 \mathrm{eB}$ & $170-300 \mathrm{eV}$ \\
$5 \mathrm{eB}$ & $280-500 \mathrm{eV}$ \\
$6 \mathrm{eB}$ & $380-680 \mathrm{eV}$ \\
& \\
\hline $7 \mathrm{eB}$ & $610-1100 \mathrm{eV}$ \\
$8 \mathrm{eB}$ & $940-1700 \mathrm{eV}$ \\
$9 \mathrm{eB}$ & $1.5-2.7 \mathrm{keV}$ \\
$10 \mathrm{eB}$ & $2.8-5.0 \mathrm{keV}$ \\
& \\
\hline $11 \mathrm{eB}$ & $4.1-7.2 \mathrm{keV}$ \\
$12 \mathrm{eB}$ & $5.8-10 \mathrm{keV}$ \\
$13 \mathrm{eB}$ & $9.8-17 \mathrm{keV}$ \\
$14 \mathrm{eB}$ & $14-24 \mathrm{keV}$ \\
& \\
\hline $15 \mathrm{eB}$ & $26-46 \mathrm{keV}$ \\
\hline
\end{tabular}

*See also Frank [1966b]

**Analyzer constant is $7.3 \mathrm{eV}$ (volt) ${ }^{-1}$ 


\section{Observations}

An example of the LEPEDEA ' $B$ ' responses to low-energy proton and electron intensities in the earth's magnetosphere is provided in Figure $I$ which displays the counting rate profiles of channels $12 \mathrm{eB}$ (electrons, $5.8 \leq \mathrm{E} \leq 10 \mathrm{keV}$ ) and $15 \mathrm{pB}$ (protons, $30 \leq E \leq 48 \mathrm{keV}$ ) and of the $213 \mathrm{~B}$ G.M. tube as functions of magnetic shell parameter I for the outbound pass of OGO 3 on 13 June 1966. Several useful position coordinates for these observations, geomagnetic latitude $\left(\lambda_{\mathrm{m}}\right)$, solar magnetospheric latitude $\left(\theta_{\mathrm{SM}}\right)$ [Ness, 1965], and solar ecliptic latitude and longitude $\left(\theta_{\mathrm{SE}}\right.$, $\varphi_{\mathrm{SE}}$ ) are shown in Figure 2. The motion of the spacecraft during this period was characterized by a trace from $\mathrm{L}=6.5$ to 16 through the late evening sector of the earth's magnetosphere at moderate solar ecliptic and solar magnetospheric latitudes $\left(\theta_{\mathrm{SE}}, \theta_{\mathrm{SM}} \sim 35^{\circ}\right)$; the axes of the fields of view of the LEPEDEA ' $B$ ' electrostatic analyzers and of the $213 B$ G. M. tube were directed within $\lesssim 30^{\circ}$ of the anti-solar direction throughout the period of observations shown in Figure 1 (see Appendix, Table V). Although no comparison of these observations with simultaneous measurements of the magnetic fields is provided 
here, all observations were obtained at geocentric radial distances $\lesssim 16 \mathrm{R}_{\mathrm{E}}$ in the late evening sector of the magnetosphere and can be positioned interior to the magnetopause with good certainty by comparison of the OGO 3 trajectory during this period with IMP I observations of the position of the magnetopause [Ness, Scearce and Scek, 1964].

Salient features of the observations presented in Figure I include (a) a decrease in proton ( $30 \leq E \leq 48 \mathrm{keV}$ ) intensities coincident with a decrease in electron ( $\mathrm{E}>45 \mathrm{keV}$ ) intensities at $\mathrm{L} \simeq 7.5$ to $8.0,(\mathrm{~b})$ an increase in electron $(5.8 \leq \mathrm{E} \leq 10 \mathrm{keV})$ intensities by a factor $\sim 40$ coincident with the decrease in electron ( $\mathrm{E}>45 \mathrm{keV}$ ) and proton $(30 \leq \mathrm{E} \leq 48 \mathrm{keV})$ intensities at $I \simeq 7.5$ to 8.0 and (c) the occurrence of intensity 'spikes' beyond $\mathrm{L} \simeq 9$ in each of the three intensity profiles. These sporadic increases in proton $(30 \leq E \leq 48 \mathrm{keV})$ and electron $(5.8 \leq \mathrm{E} \leq 10 \mathrm{keV}$ and $\mathrm{E}>45 \mathrm{keV})$ intensities beyond $\mathrm{L} \simeq 9$ are coincident within the resolution of the abridged set of observations summarized in Figure 1. (For example, approximately $3 \times 10^{3}$ individual telemetered samples of the responses of each of these three channels, and of each of the remaining 63 channels not displayed in Figure 1, are available during the period of 
this single segment of data.) Although several increases of proton $(30 \leq \mathrm{E} \leq 48 \mathrm{keV})$ and electron $(5.8 \leq \mathrm{E} \leq 10 \mathrm{keV})$ intensities occur without a measurable increase in electron $(\mathrm{E}>45 \mathrm{keV})$ intensities reflected in the responses of the 213B G.M. tube at $\mathrm{L} \gtrsim 13$, such an observation may be a manifestation of tie generaliy uecreasing charactor of the intensities as a function of $I$ to intensity levels below the threshold of the G.M. tube, $\sim 2 \times 10^{3}\left(\mathrm{~cm}^{2}-\mathrm{sec}-\mathrm{sr}\right)^{-1}$. The electron $(5.8 \leq \mathrm{E} \leq 10 \mathrm{keV})$ and proton $(30 \leq \mathrm{E} \leq 48 \mathrm{keV})$ intensities are, in an average sense, decreasing with increasing L-value beyond $\mathrm{L} \simeq 8.0$; these decreases in intensities from $\mathrm{I} \simeq 8.0$ to 15 are by factors $\sim 200$ and $\sim 10$, respectively, for the outbound pass on 13 June 1966. The relatively high electron ( $5.8 \leq \mathrm{E} \leq 10 \mathrm{keV})$ channel counting rates over $I \simeq 7.5$ to 13.5 shown in Figure $I$ are characteristic of the responses of the present instrumentation in the region of large low-energy electron intensities in the dark hemisphere of the magnetosphere beyond $L \sim 8$ reported by Gringauz and co-workers [1960, 1963] and by Freeman [1964] (see Frank [1966b] for detailed measurements of electron differential energy spectrums, energy densities, omnidirectional integral intensities, etc.). For the 'spike' of intensities at $\mathrm{I} \simeq 13.2$, typical electron ( $170 \mathrm{eV} \leq \mathrm{E} \leq 46 \mathrm{keV}$ ) energy densities and number densities are 
$3( \pm 1) \times 10^{-9} \mathrm{erg}(\mathrm{cm})^{-3}$ and $0.7( \pm 2)$ electrons $(\mathrm{cm})^{-3}$ and typical proton (190 eV $\leq \mathrm{E} \leq 48 \mathrm{keV}$ ) energy densities and number densities are $4( \pm 2) \times 10^{-9} \mathrm{erg}(\mathrm{cm})^{-3}$ and $0.6( \pm 2)$ protons $(\mathrm{cm})^{-3}$, respectively. These values are judged to be accurate within a factor of 2 (see Frank [1966b] for discussion of calculations of these omnidirectional quantities). The equalities of proton and electron energy densities and number densities within the above energy ranges and experimental error are characteristic of the present observations of the intensity 'spikes' observed in the midnight and evening sectors of the magnetosphere but exceptions to this situation have already been found and will be discussed in a later, more thorough analysis.

The rapid decrease of electron ( $\mathbb{E}>45 \mathrm{keV}$ ) intensities at $I \simeq 7.5$ to 8.0 bracketed at lower L-values by a relatively smooth, high intensity profile and at higher L-values by a fluctuating, lower intensity profile as exemplified in Figure 1 has been interpreted as delineating the outermost boundary of the durable trapping of charged particles in the magnetosphere [cf Frank, 1966c; Anderson, 1965]. This interpretation is further supported by the similar behavior of the profile of 
proton $(30 \leq \mathrm{E} \leq 48 \mathrm{keV})$ intensities and the discontinuity in the electron $(5.8 \leq \mathrm{E} \leq 10 \mathrm{keV})$ intensity profile at $I \simeq 7 \cdot 5$.

Another example of low-energy proton and electron intensities as functions of magnetic shell parameter $\mathrm{L}$ is shown in Figure 3 for $\mathrm{I} \simeq 3.3$ to 14.5 during the outbound pass on 15 June 1966. Several useful coordinates for this segment of data are displayed in Figure 4 and directions of the axes of the fields of view are summarized in the Appendix. The profiles of proton $(450 \leq \mathrm{E} \leq 720 \mathrm{eV}$ and $16 \leq \mathrm{E} \leq 26 \mathrm{keV}$ ) and electron $(1.5 \leq E \leq 2.7 \mathrm{keV})$ intensities shown in Figure 3 reveal several interesting features of the distributions of lowenergy charged particles within the magnetosphere, (a) a narrow region of proton $(450 \leq \mathrm{E} \leq 720 \mathrm{eV})$ intensities centered at $\mathrm{L}=4$ with width $\Delta \mathrm{I} \simeq 1$, (b) significant proton $(16 \leq \mathrm{E} \leq$ $26 \mathrm{keV}$ ) intensities above background responses of the instrumentation in a region extending from $L \simeq 5.0$ to 9.0, (c) a third locale at $I \simeq 9$ to $I 2$ with relatively low proton $(450 \leq \mathrm{E} \leq 720 \mathrm{eV}$ and $16 \leq \mathrm{E} \leq 26 \mathrm{keV})$ intensities but with enhanced electron $(1.5 \leq E \leq 2.7 \mathrm{keV}$ ) intensities, (d) a second narrow maximum of proton $(450 \leq E \leq 720 \mathrm{eV})$ intensities centered at $\mathrm{L} \simeq 12.7$ with width $\Delta \mathrm{L} \simeq 1$, and (e) relatively constant 
intensities of electrons ( $1.5 \leq \mathrm{E} \leq 2.7 \mathrm{keV}$ ) from $\mathrm{L} \simeq 3.5$ to 9 . Unidirectional proton intensities in eight energy bandpasses in the energy range extending from $330 \mathrm{eV}$ to $48 \mathrm{keV}$ as functions of I are presented in Figures 5, 6 and 7 . It is easily noted that (a) the narrow proton maximum at $I \simeq 4$ is predominantly populated by protons with energies $\leqslant 2 \mathrm{keV}$, (b) proton ( $\mathrm{E} \gtrsim 5 \mathrm{keV}$ ) intensities are concentrated in a region extending from $L \simeq 5$ to 10 , (c) fine structure exists in the profiles of proton $(E \lesssim 26 \mathrm{keV}$ ) intensities beyond $L \simeq 8$, attributable to temporal and/or spatial variations in intensities, and (d) there is a maximum in proton $(30 \leq \mathrm{E} \leq 48 \mathrm{keV})$ intensities at $\mathrm{I} \simeq 7,4.5 \times 10^{6}\left(\mathrm{~cm}^{2}-\mathrm{sec}-\mathrm{sr}\right)^{-1}$. Proton intensities at $I=4$ are $8 \times 10^{5}\left(\mathrm{~cm}^{2}-\mathrm{sec}-\mathrm{sr}\right)^{-1}(330 \leq \mathrm{E} \leq 530 \mathrm{eV}), \lesssim 1.5 \times 10^{6}$ $\left(\mathrm{cm}^{2}-\mathrm{sec}-\mathrm{sr}\right)^{-1}(4.7 \leq \mathrm{E} \leq 7.6 \mathrm{keV})$ and $\leqslant 10^{6}\left(\mathrm{~cm}^{2}-\mathrm{sec}-\mathrm{sr}\right)^{-1}$ $(16 \leq \mathrm{E} \leq 26 \mathrm{keV})$; at $\mathrm{L}=7.5$ proton intensities are $\leq 5 \times 10^{4}$ $\left(\mathrm{cm}^{2}-\mathrm{sec}-\mathrm{sr}\right)^{-1}(330 \leq \mathrm{E} \leq 530 \mathrm{eV}), 4 \times 10^{6}\left(\mathrm{~cm}^{2}-\mathrm{sec}-\mathrm{sr}\right)^{-1}$ $(4.7 \leq \mathrm{E} \leq 7.6 \mathrm{keV})$ and $6 \times 10^{6}\left(\mathrm{~cm}^{2}-\mathrm{sec}-\mathrm{sr}\right)^{-1}(16 \leq \mathrm{E} \leq 26 \mathrm{keV})$. These unidirectional intensities were obtained at geomagnetic latitude $\lambda_{\mathrm{m}}=22^{\circ}$ (Figure 4 ) with local pitch angle $\alpha=81^{\circ}$ (see Appendix) at $I=4.0$, and $\lambda_{m}=24^{\circ}$ with $\alpha=74^{\circ}$ at $I=7.5$. A further segment of observations of low-energy proton 
intensities within the magnetosphere is summarized in Figure 8 which displays the proton intensities in six discrete energy bandpasses within the energy range $190 \mathrm{eV}$ to $26 \mathrm{keV}$ as functions of L during the outbound pass on 11 June 1966 (refer to Figure 9 and Appendix for several useful coordinates). The transition of the character of these profiles with decreasing bandpass energy from higher proton $(5.3 \leq \mathrm{E} \leq 26 \mathrm{keV})$ intensities at $\mathrm{L} \lesssim 10$ to higher proton ( $190 \leq \mathrm{E} \leq 720 \mathrm{eV}$ ) intensities at $I \gtrsim 10$ over the L-value range, 7 to 13 , is easily discernible. Proton unidirectional intensities observed during this outbound pass are similar in magnitudes to proton intensities measured at these $\mathrm{L}$ values during the outbound pass on 15 June (cf Figures 5,6 and 7) although details in the structure of the intensity profiles are dissimilar.

Simultaneous observations of the low-energy proton and electron differential energy spectrums near the low-energy proton maximum observed at $I \simeq 4$ during the outbound pass on 15 June (see Figure 5) are shown in Figure 10. These electron and proton spectrums monotonically increase with decreasing particle energy with significant response above background rates of the instrumentation to proton and electron intensities 
over the energy range extending from $190 \mathrm{eV}$ to $1.8 \mathrm{keV}$ and $280 \mathrm{eV}$ to $46 \mathrm{keV}$, respectively. The monotonic decline of the electron and proton spectrums with increasing energy over the energy range extending from $\sim 300 \mathrm{eV}$ to $2 \mathrm{keV}$ and the constant ratio of the number density of protons and electrons per unit Energy interval, $\left(\mathrm{dN} \mathrm{e}^{/ \mathrm{dF}}\right) /\left(\mathrm{dN}_{\mathrm{p}} / \mathrm{dF}\right)^{-1}=1.6( \pm 0.7)$ where $\left(d N_{e} / d E\right)$ is the differential number density of electrons, over the above energy range suggest that these low-energy proton and electron intensities are the signature of the high-energy tail of a thermalized plasma with peak differential intensities, $\frac{\mathrm{d} J}{\mathrm{dE}}$, at $\mathrm{E} \lesssim 200 \mathrm{eV}$. The energy densities and number densities of electrons (170 eV $\leq \mathrm{E} \leq 2.7 \mathrm{keV}$ ) and protons (190 eV $\leq \mathrm{E} \leq$ $2.9 \mathrm{keV})$ are each $4( \pm 2) \times 10^{-9} \mathrm{erg}(\mathrm{cm})^{-3}$ and $6( \pm 2)(\mathrm{cm})^{-3}$, respectively. These low-energy proton and electron intensities at $I \simeq 4$ are a transient and variable feature of the distribution of charged particles in this region and will be discussed in a forthcoming investigation.

The results of a preliminary comparison of the present observations of the proton differential energy spectrum over the energy range extending from $1.8 \mathrm{keV}$ to $48 \mathrm{keV}$ on 15 June 1966 and Explorer 14 measurements of the proton ( $\mathrm{E} \geq 97 \mathrm{keV}$ ) 
spectrum at $I=6.0$ in late 1962 are summarized in Figure 11. The proton differential energy spectrum labelled with Explorer 14 has been calculated from the integral energy spectrum at $I=6.0, E \cdot P \cdot A \cdot=65^{\circ}$ (E.P.A., equatorial pitch angle) reported by Davis [1965]; the OGO 3 observations shown in Figure 11 are also for $I=6.0$ but with E.P.A. $=45^{\circ}$. This disparity in values of E.P.A. will be reflected in the proton (E $100 \mathrm{keV}$ ) intensities by factors $\lesssim 2$ [Davis, 1965]. Although the two observations of proton spectrums do not overlap in energy and are separated by a period of almost three years, no disturbing disagreement is judged to be evident in the initial comparison of spectrums displayed in Figure 11.

Two exemplary measu einents of the low-energy proton and electron differential energy spectrums are shown in Figures 12 and 13 at positions in the late evening sector of the magnetosphere at $10.5 \mathrm{R}_{\mathrm{E}}$ on 15 June and at $15.9 \mathrm{R}_{\mathrm{E}}$ on 14 June 1966 , respectively. Salient features of these spectrums include (a) a proton spectrum which is significantly broader than the simultaneously measured electron spectrum and (b) noncoincidence of the differential intensity peaks in proton and electron spectrums (for example, the proton and electron intensity peaks are at $\sim 1.5 \mathrm{keV}$ and 
$\sim 700 \mathrm{eV}$, respectively, for the observations shown in Figure 12). Further, it is noted that the peak proton intensities are not consistently occurring at higher energies than the peak in electron intensities (see Figure 12) but also may occur at lower energies (see Figure 13). For the electron and proton cnergy spectrums displayed in Figure 12, the energy densities and number densities of protons (190 eV $\leq E \leq 48 \mathrm{keV}$ ) and electrons $(170 \mathrm{eV} \leq \mathrm{E} \leq 46 \mathrm{keV})$ are each $4( \pm 2) \times 10^{-9} \mathrm{erg}(\mathrm{cm})^{-3}$ and $I( \pm 0.5)(\mathrm{cm})^{-3}$, respectively. 


\section{Discussion}

Several initial observations of low-energy proton and electron intensities within the evening sector of the earth's magnetosphere have been presented in the preceding discussion. Many features of the spatial distributions of these low-energy charged particles within the energy range extending from $\sim 200 \mathrm{eV}$ to $50 \mathrm{keV}$ are self-evident upon perusal of the Figures. Each of the topics which have been cursorily examined here will be dealt with in future investigations with considerably more detail. However, several characteristics of these spatial distributions of lowenergy proton and electron intensities are worthy of further discussion.

It is of interest to compare the energy density of protons (190 eV $\leq \mathrm{E} \leq 48 \mathrm{keV}$ ) observed during the outbound pass of oGo 3 through the outer radiation zone on 15 June 1966 with the largest reservoir of charged particle energy within the magnetosphere which has been observed by direct detection to the present date (protons, $\mathrm{E} \geq 97 \mathrm{keV}$ [Davis, 1965]). These observations of proton $\left(190 \mathrm{eV} \leq \mathrm{E} \leq 48 \mathrm{keV}\right.$ ) energy densities at $\lambda_{\mathrm{m}}=22^{\circ}\left( \pm 2^{\circ}\right)$, the corresponding magnetic field energy density $B^{2} / 8 \pi$, and 
Explorer 14 measurements of proton $(E \geq 97 \mathrm{keV}$ ) energy densities at the geomagnetic equator during late 1962 are summarized for several values of $\mathrm{I}$ in Table III. No geomagnetic storms were reported during the period of the present OGO 3 observations [High Altitude Observatory Preliminary Report of Solar Activity, TR 773] and these $1 \mathrm{nw}-\mathrm{Tnerg}_{\mathrm{g}}$ proton intensities are presumably representative of the quiet-time proton distributions in the outer radiation zone. Although the geomagnetic latitudes and epochs of these two observations significantly differ it is clearly instructive to compare the energy densities of these two proton distributions. The ratios of proton (190 eV $\leq E \leq 48 \mathrm{keV}$ ) energy densities to proton $(\mathrm{E} \geq 97 \mathrm{keV}$ ) energy densities are $\sim 4 \times 10^{-3}$ at $\mathrm{L}=3.6$ (near peak of proton $(E \geq 97 \mathrm{keV}$ ) energy density), $\sim 1$ at $I=5.7$, and $\sim 4$ at $L=6.5$. Hence at $I \simeq 3.5$ protons within the energy range $190 \mathrm{eV}$ to $48 \mathrm{keV}$ provide an insignificant contribution to the quiet-time terrestrial ring current relative to that of the proton $(E \geq 97 \mathrm{keV})$ populations, but for $\mathrm{I} \gtrsim 5$ the proton $(190 \mathrm{eV} \leq \mathrm{E} \leq 48 \mathrm{keV}$ ) contribution to the ring current on a given L-shell is similar or greater than that attributable to proton $(E \geq 97 \mathrm{keV})$ intensities. Since the relative contribution of these two proton populations to the 
TABLE III

Comparison of OGO 3 Measurements of

Proton (190 eV $\leq \mathrm{E} \leq 48 \mathrm{keV}$ ) Energy Densities (15 June, 1966)

with Explorer 14 Observations of Proton ( $\mathrm{E} \geq 97 \mathrm{keV}$ ) Energy Densities (1962)*

\begin{tabular}{|c|c|c|c|}
\hline$I$ & $\begin{array}{c}\text { OGO } 3 \\
\text { Proton }(190 \mathrm{eV} \leq \mathrm{E} \leq 48 \mathrm{keV}) \\
\text { Energy Dencit.y, erg }(\mathrm{cm})^{-3} \\
\lambda_{\mathrm{m}}=22^{\circ}\left( \pm 2^{\circ}\right)\end{array}$ & $\begin{array}{l}\frac{B^{2}}{8 \pi}, \operatorname{erg}(\mathrm{cm})^{-3 * *} \\
\lambda_{m}=22^{\circ}\left( \pm 2^{\circ}\right)\end{array}$ & $\begin{array}{c}\text { EXPLORER } 14 * \\
\text { Proton }(\mathrm{E} \geq 97 \mathrm{keV}) \\
\text { Energy Density, } \\
\operatorname{erg}(\mathrm{cm})^{-3} \\
\lambda_{\mathrm{m}}=0^{\circ}\end{array}$ \\
\hline $\begin{array}{l}3.6 \\
4.7 \\
5.2\end{array}$ & $\begin{array}{l}1.4 \times 10^{-9} \\
5.0 \times 10^{-9} \\
2.1 \times 10^{-8}\end{array}$ & $\begin{array}{l}5.5 \times 10^{-6} \\
1.4 \times 10^{-6} \\
8.4 \times 10^{-7}\end{array}$ & $\begin{array}{l}3.2 \times 10^{-7} \\
1.1 \times 10^{-7} \\
5.6 \times 10^{-8}\end{array}$ \\
\hline $\begin{array}{l}5.7 \\
6.5 \\
7.5\end{array}$ & $\begin{array}{l}2.8 \times 10^{-8} \\
3.9 \times 10^{-8} \\
3.4 \times 10^{-8}\end{array}$ & $\begin{array}{l}5.2 \times 10^{-7} \\
2.3 \times 10^{-7} \\
1.0 \times 10^{-7}\end{array}$ & $\begin{array}{c}3.2 \times 10^{-8} \\
9.6 \times 10^{-9} \\
---\end{array}$ \\
\hline $\begin{array}{r}8.2 \\
9.5 \\
10.0\end{array}$ & $\begin{array}{l}4.1 \times 10^{-8} \\
1.3 \times 10^{-8} \\
7.1 \times 10^{-9}\end{array}$ & $\begin{array}{l}5.7 \times 10^{-8} \\
2.0 \times 10^{-8} \\
1.3 \times 10^{-8}\end{array}$ & $\begin{array}{l}-- \\
--- \\
--\end{array}$ \\
\hline
\end{tabular}

*Davis [1965]

**Jensen and Cain [1962] 
quiet-time terrestrial ring current is approximately proportional to the ratio of their total kinetic energies [cf Parker, 1966], it is also instructive to estimate the magnitude of the reservoir of kinetic energy of the proton (190 eV $\leq \mathrm{E} \leq 48 \mathrm{keV}$ ) distribution. The total kinetic energy of protons ( $\mathrm{E} \geq 97 \mathrm{keV}$ ) within the earth's magnetosphere has been shown to be $\sim 6 \times 10^{21}$ ergs [Hoffman and Bracken, 1965]; an order-of-magnitude estimate of the total proton (190 eV $\leq \mathrm{E} \leq 48 \mathrm{keV}$ ) kinetic energy for the observations reported here, assuming azimuthal symmetry over $I=5$ to 10 and a dependence of the observed energy densities (Table III) upon geomagnetic latitude $\lambda_{\mathrm{m}}$ by factors $\lesssim 3$ over $\lambda_{\mathrm{m}}=0^{\circ}$ to $30^{\circ}$, is $\sim 5 \times 10^{21} \mathrm{ergs}$, or approximately the same magnitude as the trapped proton ( $\mathrm{E} \geq 97 \mathrm{keV}$ ) energy reservoi $\because$. Hence it is quite likely that the proton (190 eV $\leq \mathrm{E} \leq 48 \mathrm{keV}$ ) contribution to the quiet-time proton ring current is similar to that due to the outer zone protons $(\mathrm{E} \geq 97 \mathrm{keV}), \sim-10 \gamma\left(1 \gamma=10^{-5}\right.$ gauss $)$ at the surface of the earth [cf Hoffman and Bracken, 1965]. Further inspection of Table III and comparison of the OGO 3 measurements of proton (190 eV $\leq E \leq 48 \mathrm{keV}$ ) energy densities with the magnetic field energy density, where $B$ has been calculated at the satellite position with the Jensen and Cain [1962] coefficients derived 
from survey data at the earth's surface, show that the proton (190 eV $\leq \mathrm{E} \leq 48 \mathrm{keV}$ ) energy densities should contribute substantially to the distortion of the geomagnetic field for $6 \lesssim L \lesssim 10$. Comparison of simultaneous OGO 3 measurements of the vector magnetic field with the above observations of charged particle intensilies is vital in determining the detailed effect of this low-energy proton distribution upon the local magnetic fields.

A narrow peak of relatively high low-energy proton and electron intensities within the energy range $\sim 300 \mathrm{eV}$ to $2 \mathrm{keV}$ at $I \simeq 4$ with width $\Delta \amalg \sim I$ has been observed during several OGO 3 traversals of the outer radiation zone (see Figures 3 and 5). The absence of the intensity peak at these L-values during many of the segments of data through this region which have been perused to date indicates that measurable intensities of these low-energy protons and electrons are a transient phenomena. The proton and electron differential energy spectrums share a common slope and an almost equal number density per unit energy interval and monotonically increase with decreasing energy over the energy range extending from $\sim 300 \mathrm{eV}$ to $2 \mathrm{keV}$, which suggest that these spectrums may be the signatures of the high energy 
tail of a thermalized plasma with peak differential intensities at $E \lesssim 200 \mathrm{eV}$. The energy densities and number densities of electrons (170 eV $\leq \mathrm{E} \leq 2.7 \mathrm{keV}$ ) and protons (190 eV $\leq \mathrm{E} \leq 2.9 \mathrm{keV}$ ) are equal, $4( \pm 2) \times 10^{-9} \mathrm{erg}(\mathrm{cm})^{-3}$ and $6( \pm 2) \mathrm{cm}^{-3}$, respectively, at the peak intensities on $\mathrm{L} \simeq 4$. The total inventory of charged particle kinetic energy over the above energy range in this region is inadequate to contribute significantly to a quiet-time terrestrial ring current.

All observations of low-energy protons presented here are in agreement with the upper limits on proton intensities in this energy range obtained with an electrostatic analyzer borne on IMP-1 as reported by Wolfe, Silva and Myers [1966]. These lowenergy proton intensities observed with oGo 3 are near or below the intensity threshold of the IMP 1 instrument. The threshold omnidirectional intensity for the IMP 1 apparatus is $7.2 \times 10^{4}$ $\left(\mathrm{cm}^{2}-\mathrm{sec}-\mathrm{ev}\right)^{-1}$ at $600 \mathrm{eV}$ [Wolfe, et al, 1966]; the threshold omnidirectional intensity for the OGO 3 IEPEDEA ' $\mathrm{B}$ ' instrument is $2.5 \times 10^{2}\left(\mathrm{~cm}^{2}-\mathrm{sec}-\mathrm{ev}\right)^{-1}$ at $585 \mathrm{eV}$.

First simultaneous observations of proton and electron differential energy spectrums over the energy range extending 
from $\sim 200 \mathrm{eV}$ to $50 \mathrm{keV}$ in the late evening sector of the earth's magnetic tail are displayed in Figures 12 and 13. Observations of intensity 'spikes' of electrons ( $\mathrm{E}>45 \mathrm{keV}$ ) associated with the high-energy tails of the electron spectrums have been reported by Frank [1965], Anderson [1965] and Anderson and Ness [1066]. Several observations of the electron (350 $\leq \mathrm{E} \leq 20 \mathrm{keV}$ ) spectrums at $\sim 17 \mathrm{R}_{\mathrm{E}}$ with the Vela satellites have been summarized by Coon [1966], and measurements over the energy range extending from $\sim 100 \mathrm{eV}$ to $50 \mathrm{keV}$ in the earth's magnetic tail at geocentric radial distances $8 R_{E}$ to $20 R_{E}$ have been recently reported by Frank [1966b]. Typical characteristics of these intensity 'spikes' at peak intensities (refer to Figure 13 for exemplary proton and electron differential energy spectrums) are (a) approximately equal proton (190 eV $\leq \mathrm{E} \leq 48 \mathrm{keV}$ ) and electron (170 eV $\leq \mathrm{E} \leq 46 \mathrm{keV}$ ) energy densities, $\sim 10^{-9} \mathrm{erg}(\mathrm{cm})^{-3}$ each, (b) approximately equal proton and electron number densities over the above energy range, $\sim 1(\mathrm{~cm})^{-3}$ each, and (c) largely dissimilar differential energy spectrums, proton spectrums with intensity peaks noncoincident with those of the electron intensity peaks and significantly broader (harder) in the high energy tail $(E \gtrsim 3 \mathrm{keV})$ than the 
relatively steep (soft) electron spectrums. Typical omnidirectional intensities of protons ( $E \geq 190 \mathrm{eV}$ ) and electrons ( $E \geq 170 \mathrm{eV})$ in the maxima of these intensity 'spikes' beyond $\sim 10 \mathrm{R}_{\mathrm{E}}$ are $\sim 5 \times 10^{7}\left(\mathrm{~cm}^{2}-\mathrm{sec}\right)^{-1}$ and $\sim 10^{9}\left(\mathrm{~cm}^{2}-\mathrm{sec}\right)^{-1}$, respectively. Finally, it is noted here that the peaks of proton ( $30 \leq \mathrm{E} \leq 48 \mathrm{keV}, 16 \leq \mathrm{E} \leq 26 \mathrm{keV}$, and $1 工 \leq \mathrm{E} \leq 18 \mathrm{keV})$ intensities occur, in a coarse manner, on lower L-shells with increasing proton energy (see Figure 7 ), which may be characteristic of radial diffusion of protons within this energy range [cf Nakada, Dungey and Hess, 1965]. For proton energies $E \lesssim I l \mathrm{keV}$ (see Figures 5 and 6) this increase of the L-shell coordinate of the 'average' peak of intensities with decreasing proton energy is not clearly evident. Further mapping of these low-energy proton intensities and a comprehensive survey of the temporal variations in intensities are now in progress. 


\section{Appendix}

The following Tables summarize the directions of the axis of the LEPEDEA 'B' field of view in several useful coordinate systems for the three consecutive outbound passes of OGO 3 through the earth's magnetosphere presented in the preceding discussions.

TABLE IV

11 JUNE 1966 (OUTBOUND)

\begin{tabular}{|c|cc|cc|c|}
\hline Satellite Position, & \multicolumn{4}{|c|}{ Axis directed along: } \\
L & \multicolumn{2}{|c|}{ Solar-ecliptic } & Solar-magnetospheric & Pitch angle*, \\
$\theta_{\mathrm{SE}}$ & $\varphi_{\mathrm{SE}}$ & $\theta_{\mathrm{SM}}$ & $\varphi_{\mathrm{SM}}$ & $\alpha^{* *}$ \\
\hline 8 & $-4^{\circ}$ & $186^{\circ}$ & $-4^{\circ}$ & $186^{\circ}$ & $76^{\circ}$ \\
10 & $-8^{\circ}$ & $191^{\circ}$ & $-7^{\circ}$ & $192^{\circ}$ & $71^{\circ}$ \\
12 & $-12^{\circ}$ & $195^{\circ}$ & $-10^{\circ}$ & $196^{\circ}$ & $65^{\circ}$ \\
\hline
\end{tabular}


TABLE V

$13 \pi$ JNE 1966 (OUTBOUND)

\begin{tabular}{|c|c|c|c|c|c|}
\hline \multirow[t]{2}{*}{$\begin{array}{c}\text { Satellite Position, } \\
\text { I }\end{array}$} & \multicolumn{4}{|c|}{ Axis directed along: } & \multirow{2}{*}{$\begin{array}{c}\text { Pitch angle*, } \\
\alpha^{* *}\end{array}$} \\
\hline & $\theta_{\mathrm{SE}}$ & $\varphi_{\mathrm{SE}}$ & $\theta_{\mathrm{SM}}$ & $\varphi_{\mathrm{SM}}$ & \\
\hline 7 & $-1^{\circ}$ & $182^{\circ}$ & $-1^{\circ}$ & $182^{\circ}$ & $77^{\circ}$ \\
\hline 8 & $-3^{0}$ & $185^{\circ}$ & $-3^{\circ}$ & $185^{\circ}$ & $75^{\circ}$ \\
\hline 10 & $-8^{\circ}$ & $190^{\circ}$ & $-7^{\circ}$ & $191^{\circ}$ & $70^{\circ}$ \\
\hline 12 & $-12^{\circ}$ & $194^{\circ}$ & $-10^{\circ}$ & $195^{\circ}$ & $63^{\circ}$ \\
\hline 14 & $-16^{\circ}$ & $197^{\circ}$ & $-13^{\circ}$ & $198^{\circ}$ & $55^{\circ}$ \\
\hline 16 & $-19^{\circ}$ & $198^{\circ}$ & $-18^{\circ}$ & $199^{\circ}$ & $48^{\circ}$ \\
\hline
\end{tabular}


TABLE VI

15 JUNE 1966 (OUTBOUND)

\begin{tabular}{|c|cc|cc|c|}
\hline Satellite Position, & \multicolumn{5}{|c|}{ Axis directed along: } \\
L & \multicolumn{2}{|c|}{ Solar-ecliptic } & Solar-magnetospheric & Pitch angle*, \\
& $\theta_{\mathrm{SE}}$ & $\varphi_{\mathrm{SE}}$ & $\theta_{\mathrm{SM}}$ & $\varphi_{\mathrm{SM}}$ & $\alpha^{* *}$ \\
\hline 4 & $5^{\circ}$ & $168^{\circ}$ & $5^{\circ}$ & $168^{\circ}$ & $81^{\circ}$ \\
5 & $3^{\circ}$ & $174^{\circ}$ & $3^{\circ}$ & $174^{\circ}$ & $79^{\circ}$ \\
6 & $1^{\circ}$ & $178^{\circ}$ & $1^{\circ}$ & $178^{\circ}$ & $77^{\circ}$ \\
8 & $-3^{\circ}$ & $185^{\circ}$ & $-3^{\circ}$ & $185^{\circ}$ & $73^{\circ}$ \\
10 & $-7^{\circ}$ & $189^{\circ}$ & $-6^{\circ}$ & $191^{\circ}$ & $68^{\circ}$ \\
12 & $-11^{\circ}$ & $193^{\circ}$ & $-9^{\circ}$ & $194^{\circ}$ & $62^{\circ}$ \\
14 & $-15^{\circ}$ & $196^{\circ}$ & $-13^{\circ}$ & $197^{\circ}$ & $55^{\circ}$ \\
\hline
\end{tabular}

$* \vec{B}$ derived from Jensen and Cain [1962] coefficients **Convention: if particle velocity vector $\overrightarrow{\mathrm{v}} \| \overrightarrow{\mathrm{B}}, \alpha \equiv 0^{\circ}$ 
Acknowledgements

The author is indebted to Dr. J. A. Van Allen for his support throughout the various phases of this research. The efforts of D. C. Enemark, N. K. Henderson, R. H. Gabel, W. W. Stanley, R. D. Carlson, R. F. Randall, R. L. Swisher and D. Klumpar during the design and construction phases, I. Shope and $\mathrm{C}$. Brues of the University of Iowa during the computer analysis phase, and Dr. G. H. Ludwig, Dr. E. Mercanti, D. Krueger, E. Moyer and many other members of the Goddard Space Flight Center personnel during the multitudinous phases of spacecraft integration and launch operations are acknowledged with great pleasure.

This research was supported in part by the National Aeronautics and Space Administration under Grant NsG-233-62 and Contract NAS5-2054 and by the Office of Naval Research under Contract Nonr-1509(06). 


\section{References}

Anderson, K. A, Energetic electron fluxes in the tail of the geomagnetic field, J. Geophys. Res., 70, 474I-4763, 1965.

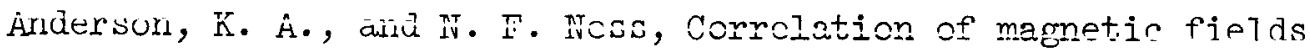
and energetic electrons on the IMP I satellite, J. Geophys. Res., 71, 3705-3727, 1966.

Cahill, I. J., Inflation of the magnetosphere near 8 earth radii in the dark hemisphere, J. Geophys. Res., 71, $4505-4519,1966$.

Coon, James, Vela satellite measurements of particles in the solar wind and the distant geomagnetosphere, Radiation Trapped in the Earth's Magnetic Field, ed. by B. M. McCormac, D. Reidel, 231-255, 1966.

Davis, L. R., Low energy trapped protons and electrons, Proceedings of the Plasma Space Science Symposium, ed. by C. C. Chang and S. S. Huang, 214-226, 1965.

Frank, I. A., A survey of electrons $E>40 \mathrm{keV}$ beyond 5 earth radii with Explorer XIV, J. Geophys. Res., 70, 1593$1626,1965$. 
Frank, L. A., Explorer 12 observations of the temporal variations of low-energy electron intensities in the outer radiation zone during geomagnetic storms, J. Geophys. Res., II, 4631-4639, 1966a.

Frank, I. A., Initial observations of low-energy electrons in the earth's magnetosphere with oGO $\overline{3}$, accepted for publication (September), J. Geophys. Res., $1966 \mathrm{~b}$.

Frank, L. A., Observations of magnetospheric boundary phenomena, Radiation Trapped in the Earth's Magnetic Field, ed. by B. M. McCormac, D. Reidel, 422-446, 1966 c.

Freeman, J. W., The morphology of the electron distribution in the outer radiation zone and near the magnetospheric boundary as observed by Explorer XII, J. Geophys. Res., 69, 1691-1723, 1964 .

Gringauz, K. I., V. G. Kurt, V. I. Moroz, and I. S. Shklovskii, Results of observations of charged particles observed out to $R=100,000 \mathrm{~km}$, with the aid of charged-particle traps on Soviet space rockets, Astron. Zh., 37, 716-735 (1960; translation in: Soviet Astronomy-A.J., 4, 680$695,1961)$. 
Gringauz, K. I., V. V. Bezrukikh, I. S. Musatov, R. E. Rybchinsky, and S. M. Sheronova, Measurements made in the earth's magnetosphere by means of charged particle traps aboard the Mars I probe, Space Research, IV, 621-626, 1963. Hoffman, R. A., and P. A. Bracken, Magnetic effects of the quict time proton belt, I. Genphys. Res.: 70, 35413556,1965 .

Jensen, D. C., and J. C. Cain, An interim geomagnetic field (abstract), J. Geophys. Res., 67, 3568-3569, 1962. Nakada, M. P., J. W. Dungey, and W. N. Hess, on the origin of outer-belt protons, 1., J. Geophys. Res., 70, 3529$3532,1965$.

Ness, N. F., The earth's magnetic tail, J. Geophys. Res., 70, $2989-3003,1965$.

Ness, N. F., C. S. Scearce, and J. B. Seek, Initial results of the IMP-I magnetic field experiment, J. Geophys. Res., 69, 3531-3569, 1964.

Parker, E. N., Particle effects in the geomagnetic field, Radiation Trapped in the Earth's Magnetic Field, ed. by B. M. McCormac, D. Reidel, 302-320, 1966. 
Wolfe, J.H., R. W. Silva, and M. A. Myers, Observations of the solar wind during the flight of IMP I, J. Geophys. Res., 1ㅡ, 1319-1340, 1966. 


\section{Figure Captions}

Figure 1. The responses of two of the OGO 3 LEPEDEA ' $B$ ' (IEPEDEA, LOw Energy Proton and Electron Differential Energy Analyzer) channels, electrons $(5.8 \leq E \leq 10 \mathrm{keV})$ and proiuns ( $30 \leq \mathbb{E} \leq 1,8$ rev), and of the thin-windowed 213B G.M. tube as functions of magnetic shell parameter I for the outbound pass on 13 June 1966.

Figure 2. Several useful position coordinates for OGO 3 on 13 June 1966 (outbound pass, Figure 1).

Figure 3. Responses of three of the OGO 3 LEPEDEA ' $B$ ' channels, protons $(450 \leq \mathrm{E} \leq 720 \mathrm{eV}$ and $16 \leq \mathrm{E} \leq 26 \mathrm{keV}$ ) and electrons ( $1.5 \leq \mathrm{E} \leq 2.7 \mathrm{keV}$ ) as functions of $\mathrm{L}$ for the outbound pass on 15 June 1966.

Figure 4. Several useful position coordinates for OGO 3 on 15 June 1966 (outbound pass, Figure 3).

Figure 5. Unidirectional intensities of protons $(330 \leq \mathrm{E} \leq 530 \mathrm{eV}$, $450 \leq E \leq 720 \mathrm{eV}$ and $1.8 \leq E \leq 2.9 \mathrm{keV}$ ) as functions of I for the outbound OGO 3 traversal of the outer radiation zone. Intensities are plotted as $\bullet$, upper limits as 0 . 
Figure 6. Continuation of Figure 5 for protons $(4.7 \leq \mathrm{E} \leq 7.6 \mathrm{keV}$ and $6.7 \leq \mathrm{E} \leq 11 \mathrm{keV})$.

Figure 7. Continuation of Figure 5 for protons ( $11 \leq E \leq 18 \mathrm{keV}$, $16 \leq \mathrm{E} \leq 26 \mathrm{keV}$ and $30 \leq \mathrm{E} \leq 48 \mathrm{keV})$.

Figure 8. Proton unidirectional intensities within six energy bandpasses of LEEEDEA ' $B$ ' as functions of I for $I=7.5$ to 12.5 as observed during the outbound pass on II June 1966.

Figure 9. Several useful position coordinates for OGO 3 on 11 June 1966 (outbound pass, Figure 8).

Figure 10. Simultaneous observations of low-energy proton and electron differential energy spectrums at $L=3.9$, 07:04 U.T. on 15 June 1966.

Figure 1l. Comparison of OGO 3 observations of the proton (1.8 $\leq \mathrm{E} \leq 48 \mathrm{keV})$ differential energy spectrum on 15 June 1966 with Explorer 14 measurements of the proton ( $E \geq 97 \mathrm{keV}$ ) spectrum in Iate 1962 as reported by Davis [1965] at $I=6.0, \lambda_{m}=24^{\circ}$. (E.P.A., equatorial pitch angle). Omnidirectional intensities of protons ( $1.8 \leq \mathrm{E} \leq 48 \mathrm{keV}$ ) are $2( \pm 1) \times 10^{8}\left(\mathrm{~cm}^{2}-\mathrm{sec}\right)^{-1}$ at this position in the outer radiation zone. 
Figure 12. Simultaneous observations of proton and electron spectrums at geocentric radial distance $10.5 \mathrm{R}_{\mathrm{E}}$ on 15 June 1966. If these spectrums are described by a power law, $\frac{\partial J}{\partial E}=\mathrm{kE}^{-\mathrm{n}}$, for $\mathrm{E} \gtrsim 3 \mathrm{keV}$, then $\mathrm{n} \simeq 1.8$ for the proton spectrum and $n \simeq 3.8$ for the electron spectrum. (See also Finure 3 for position rolative to charged particle distributions.)

Figure 13. An example of simultaneous observations of proton and electron spectrums in the late evening sector of the earth's magnetic tail at $15.9 \mathrm{R}_{\mathrm{E}}$ on 14 June 1966. The sun-earth-probe (satellite) angle, $\chi_{\mathrm{SEP}}$, was $139^{\circ}$. 


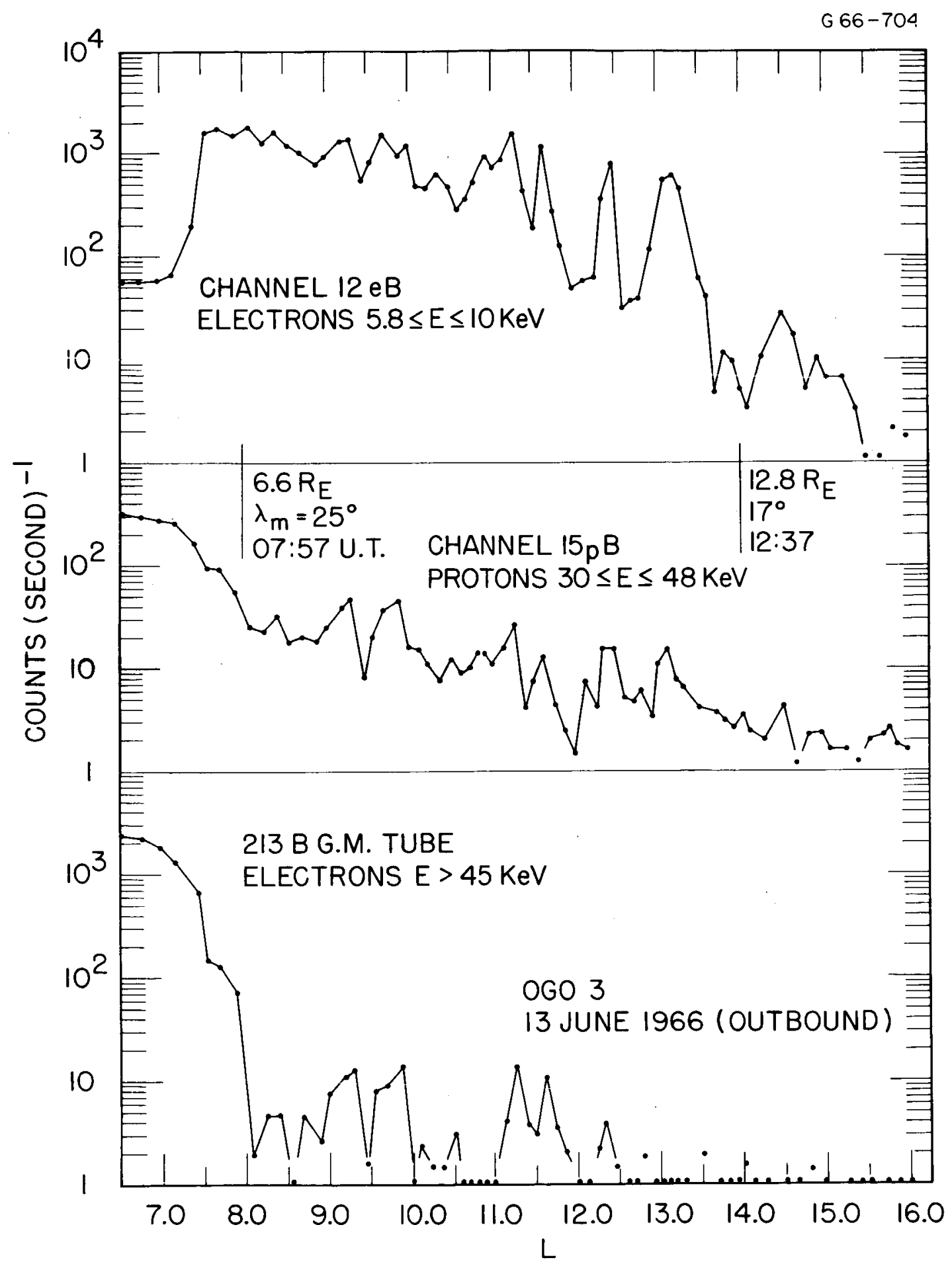

Figure 1 


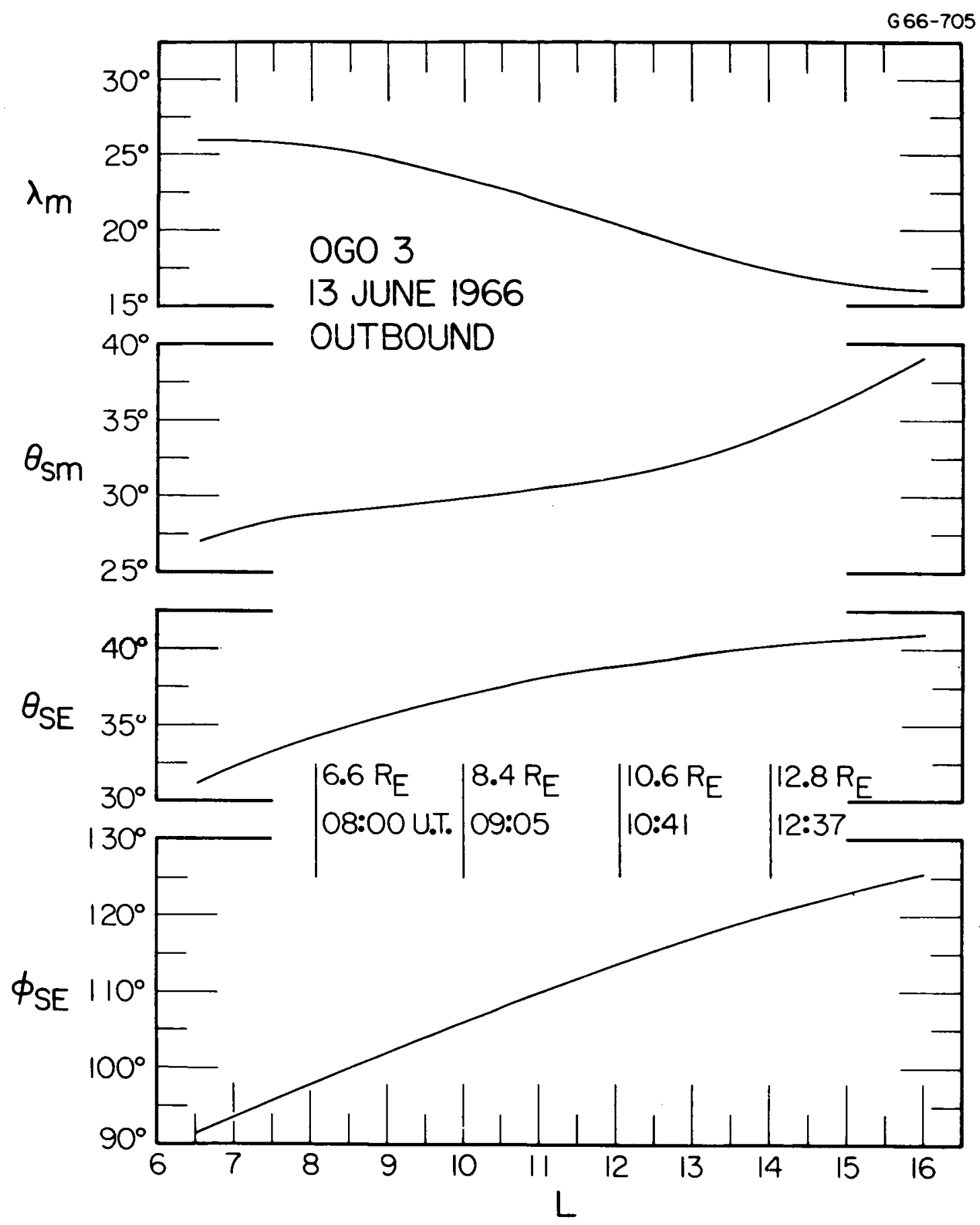

Figure 2 


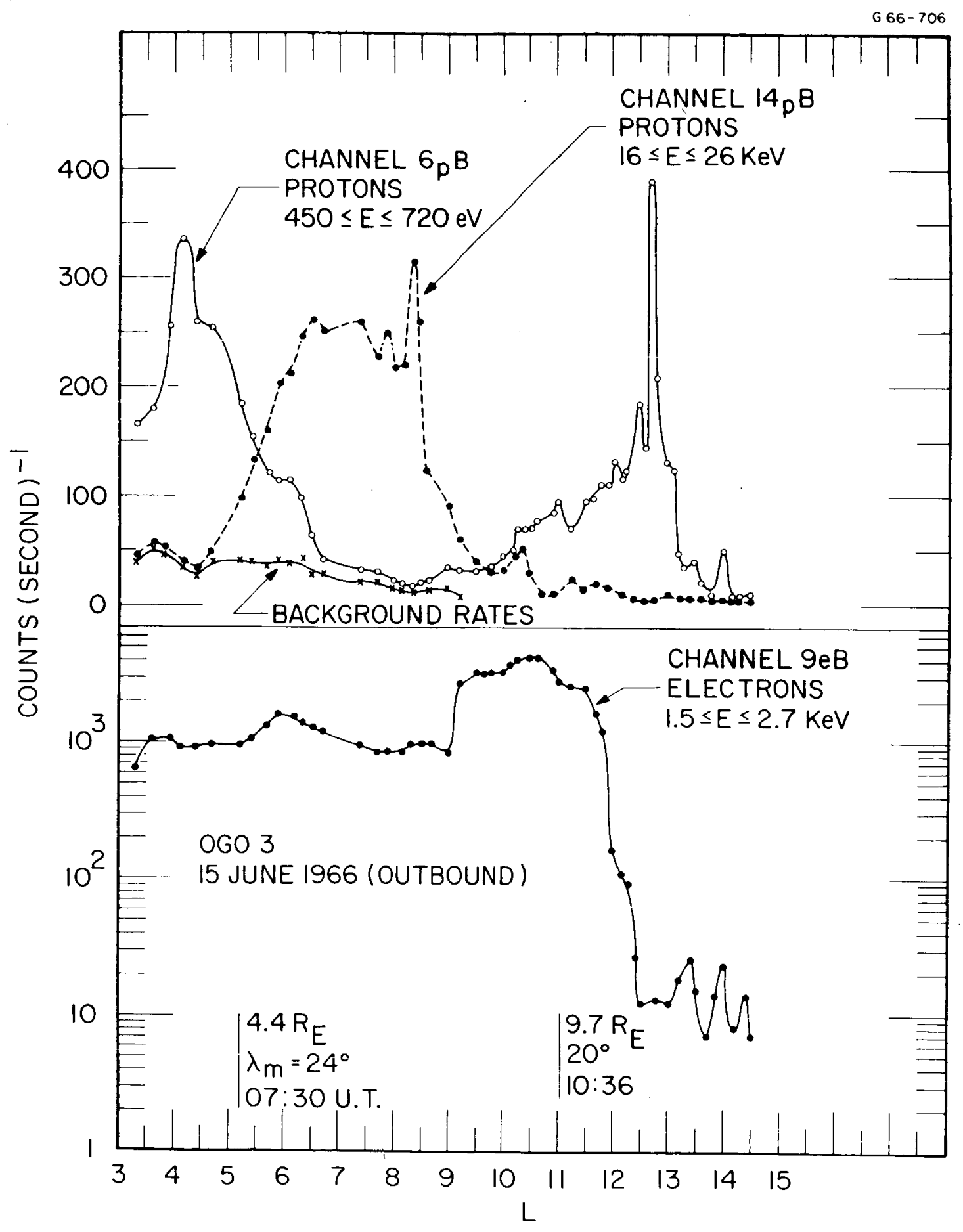

Figure 3 


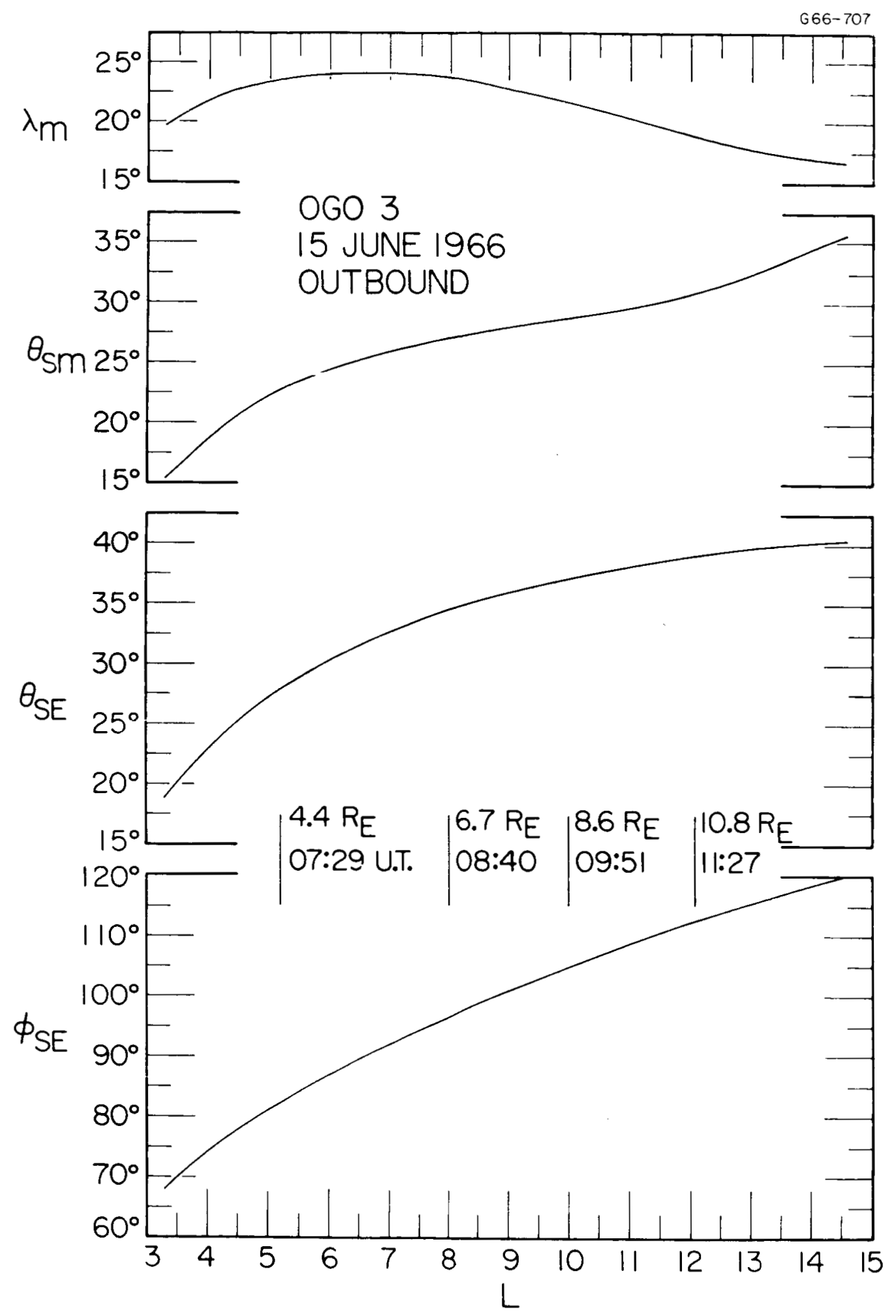

Figure 4 


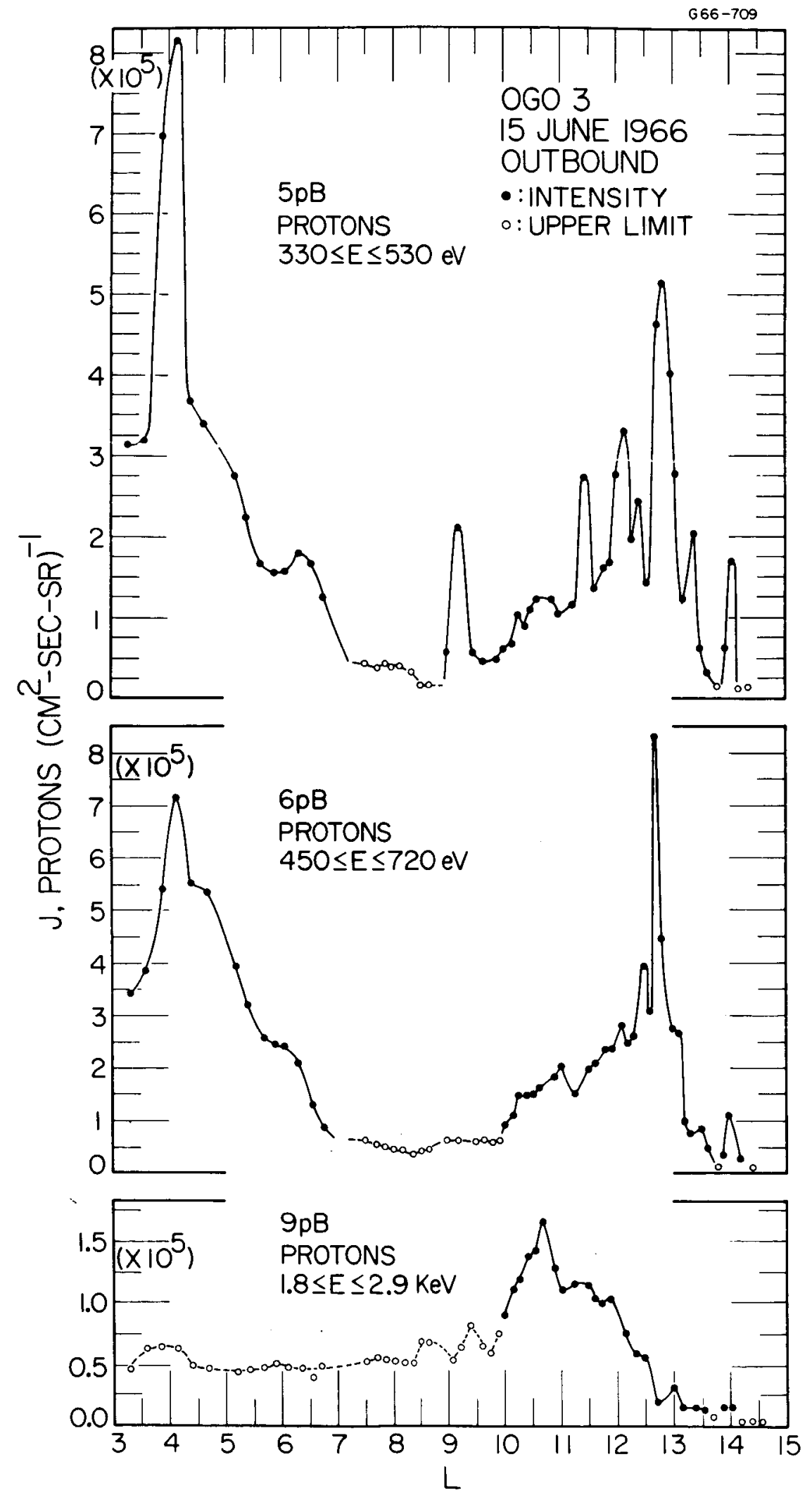

Figure 5 


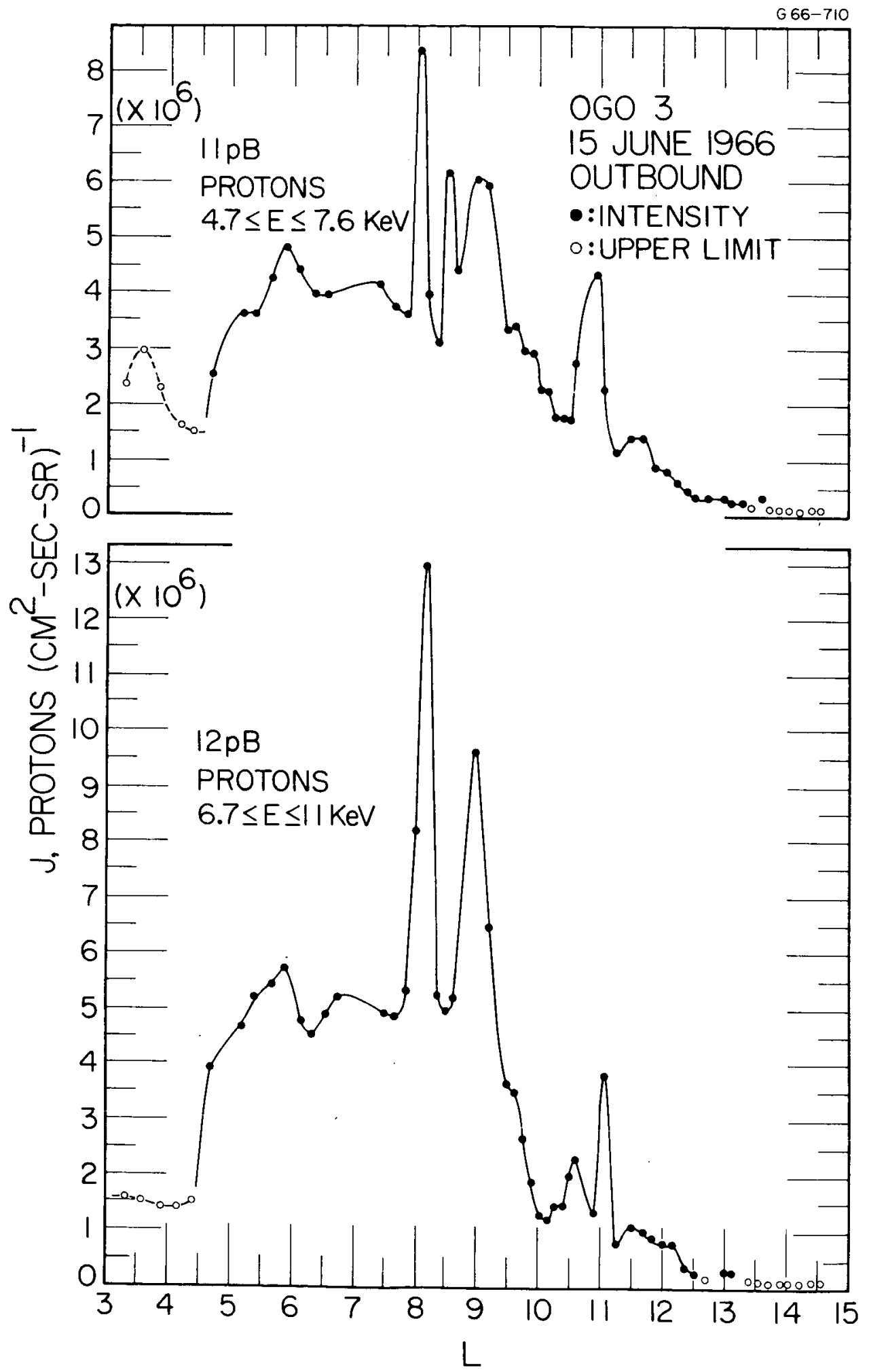

Figure 6 


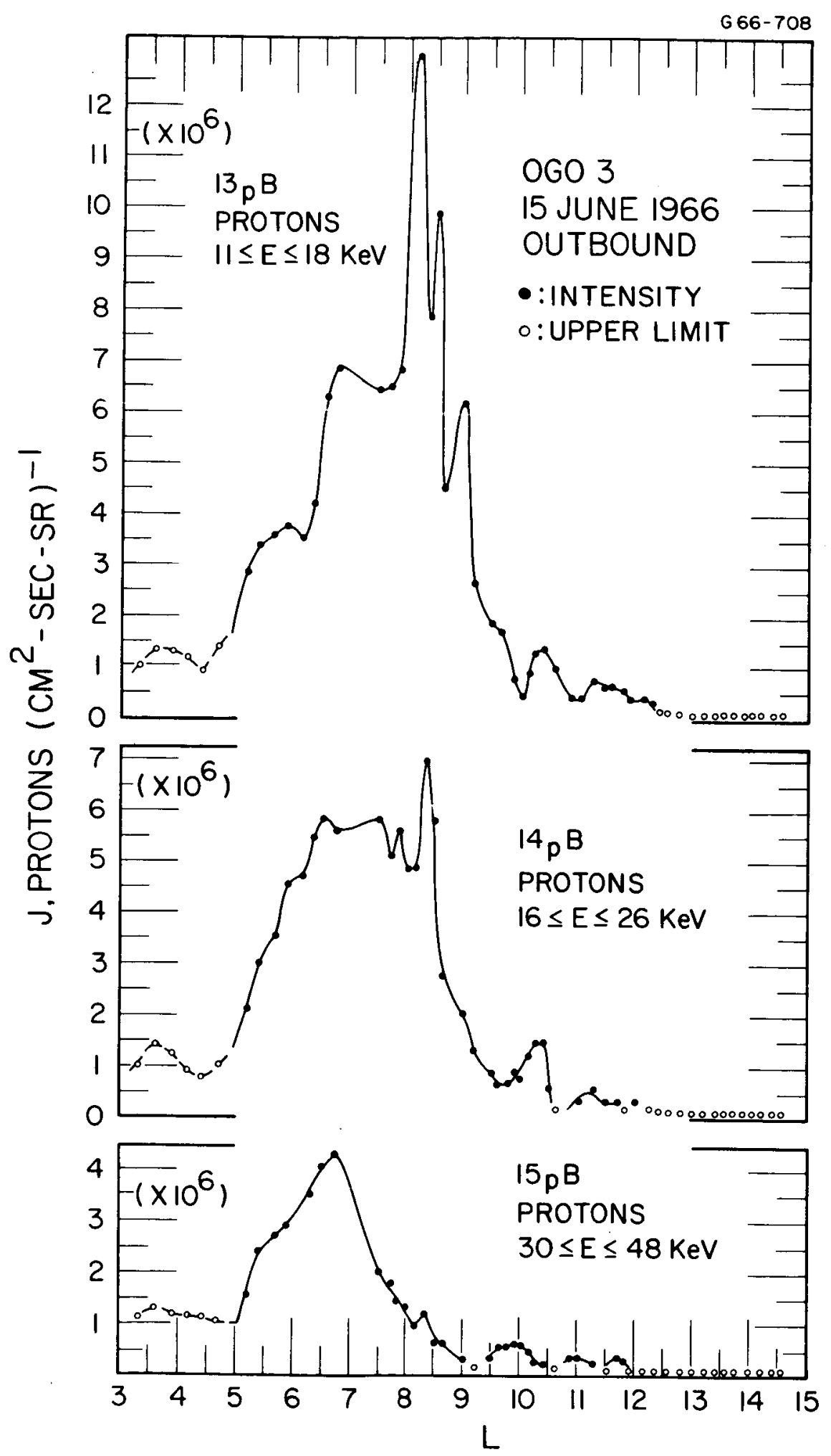

Figure 7 


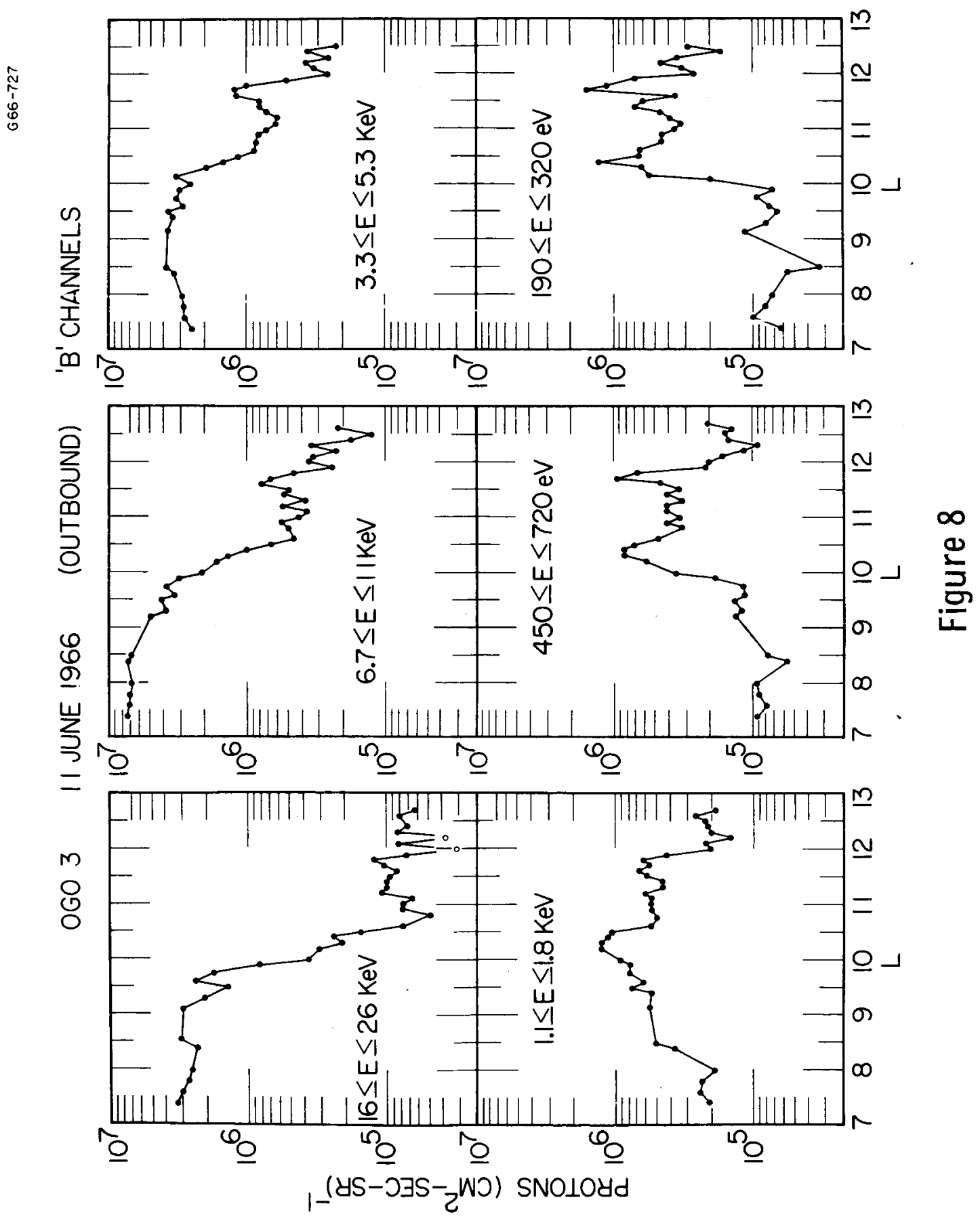




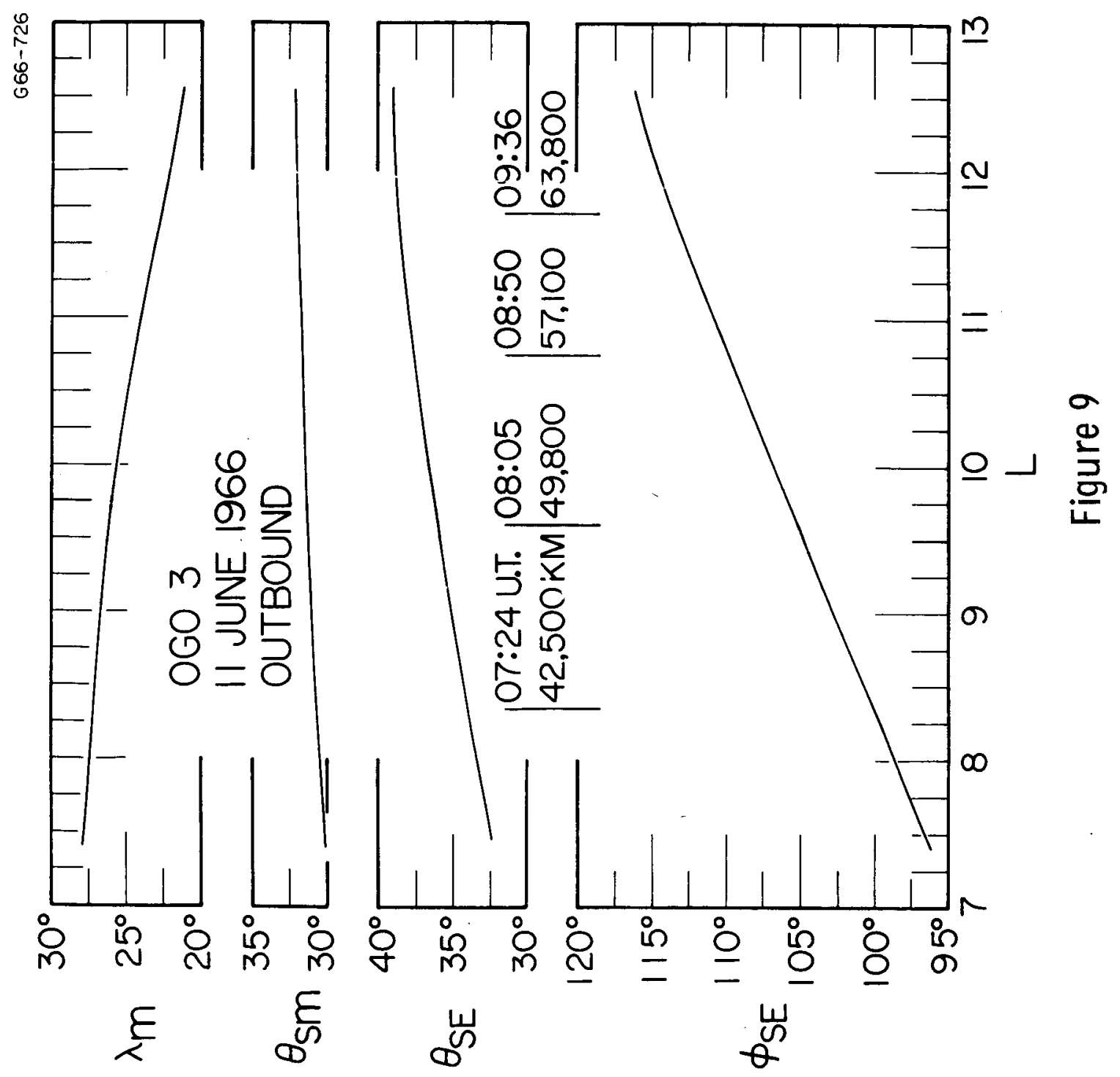




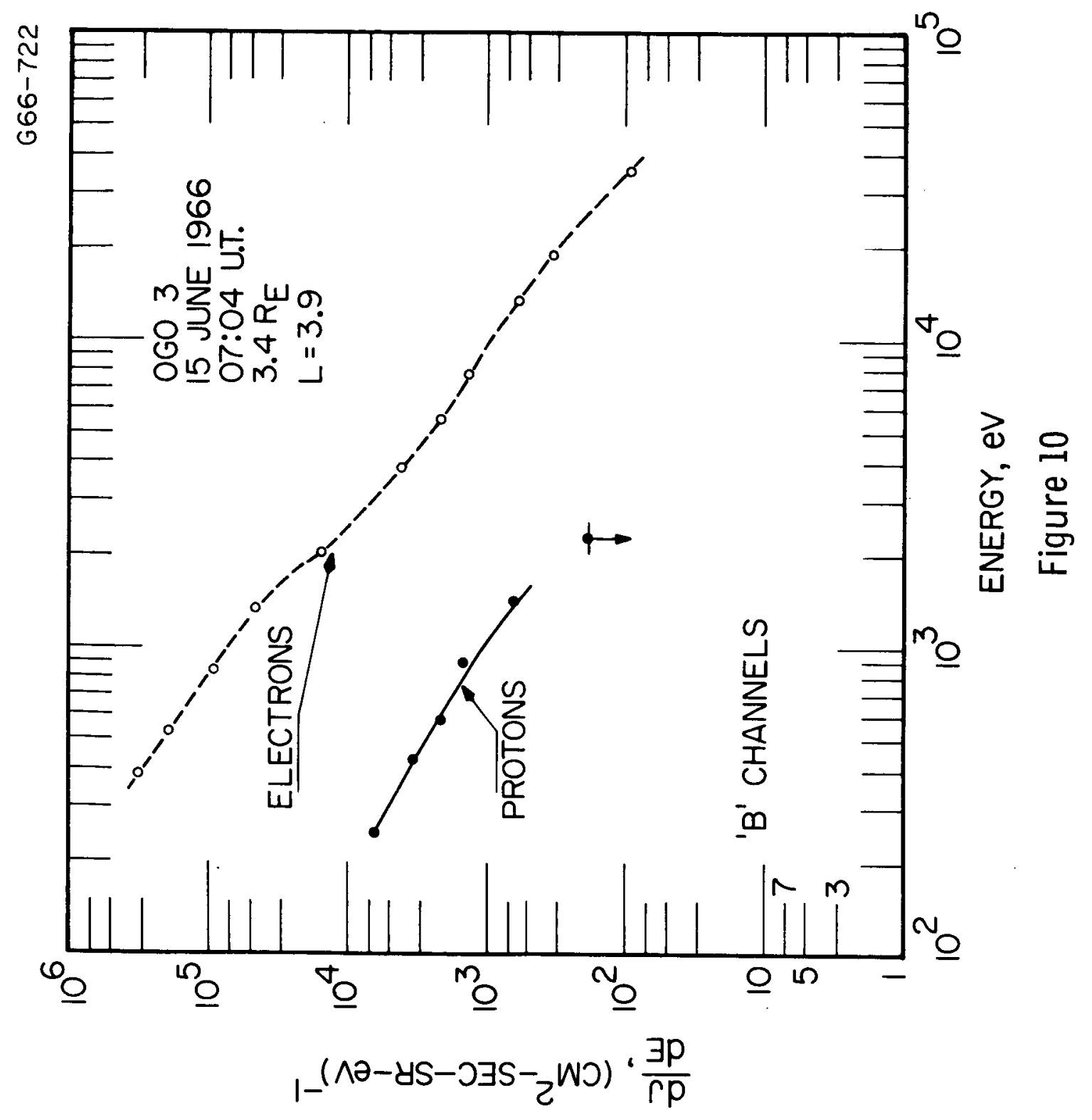




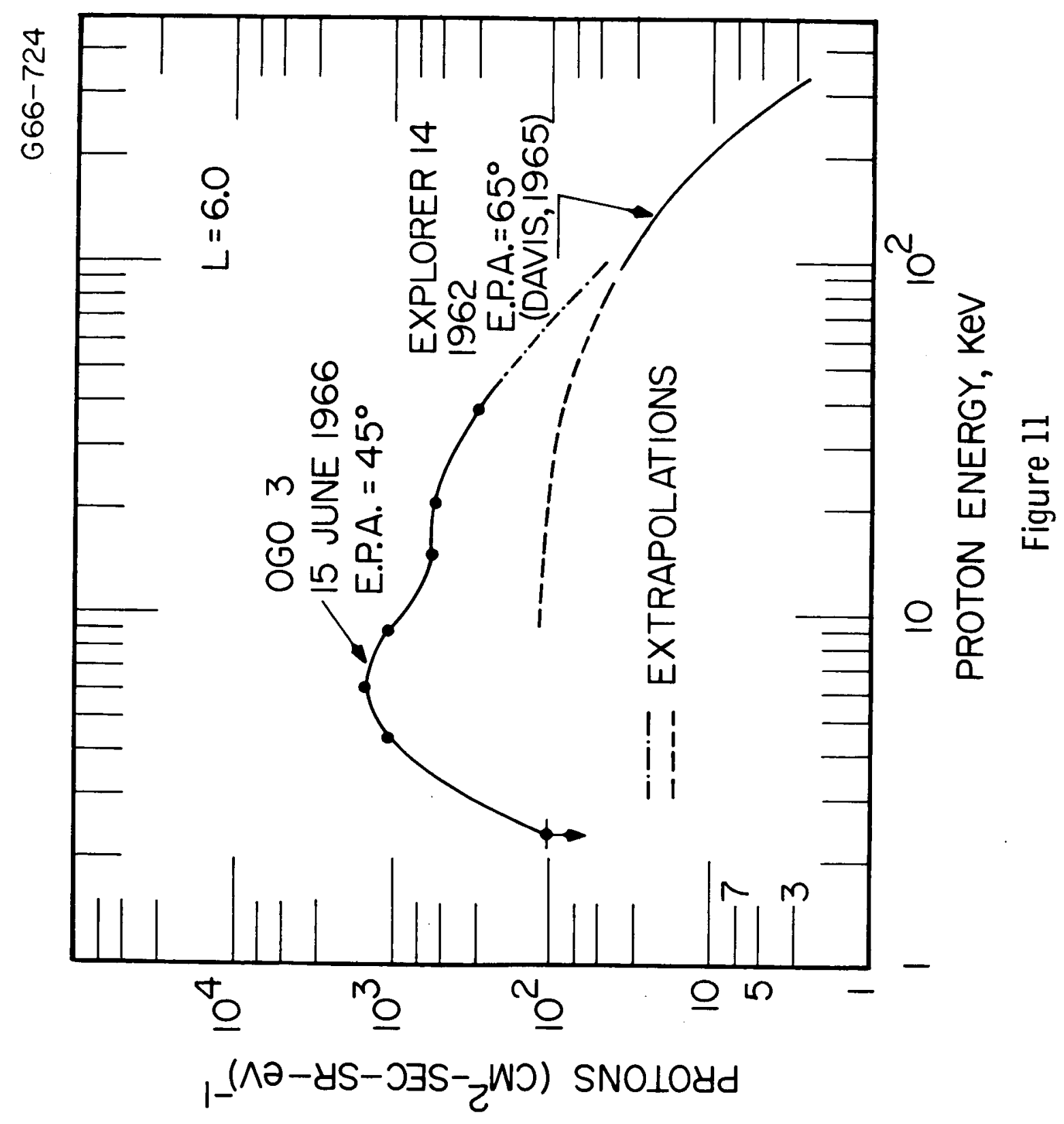




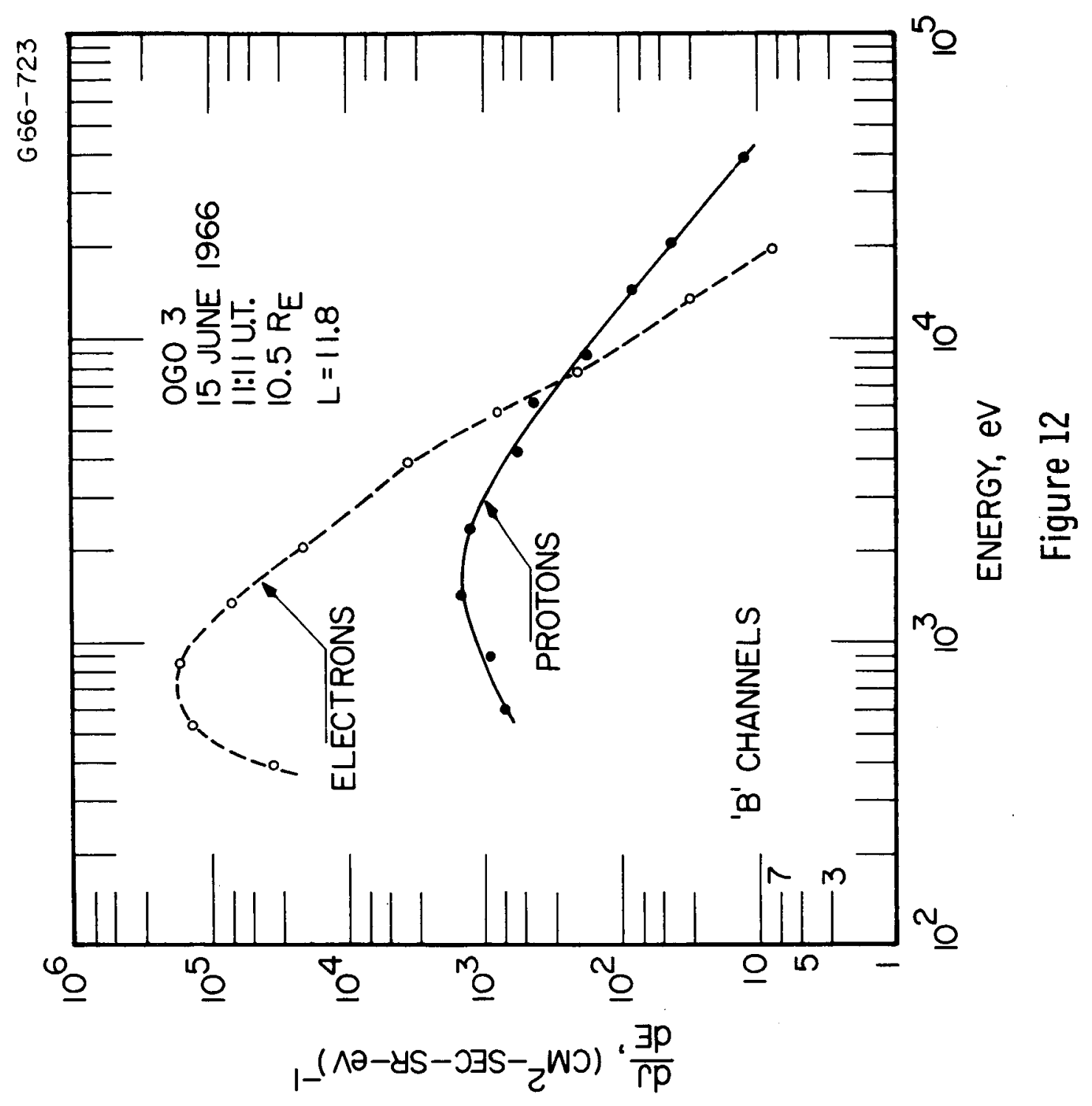




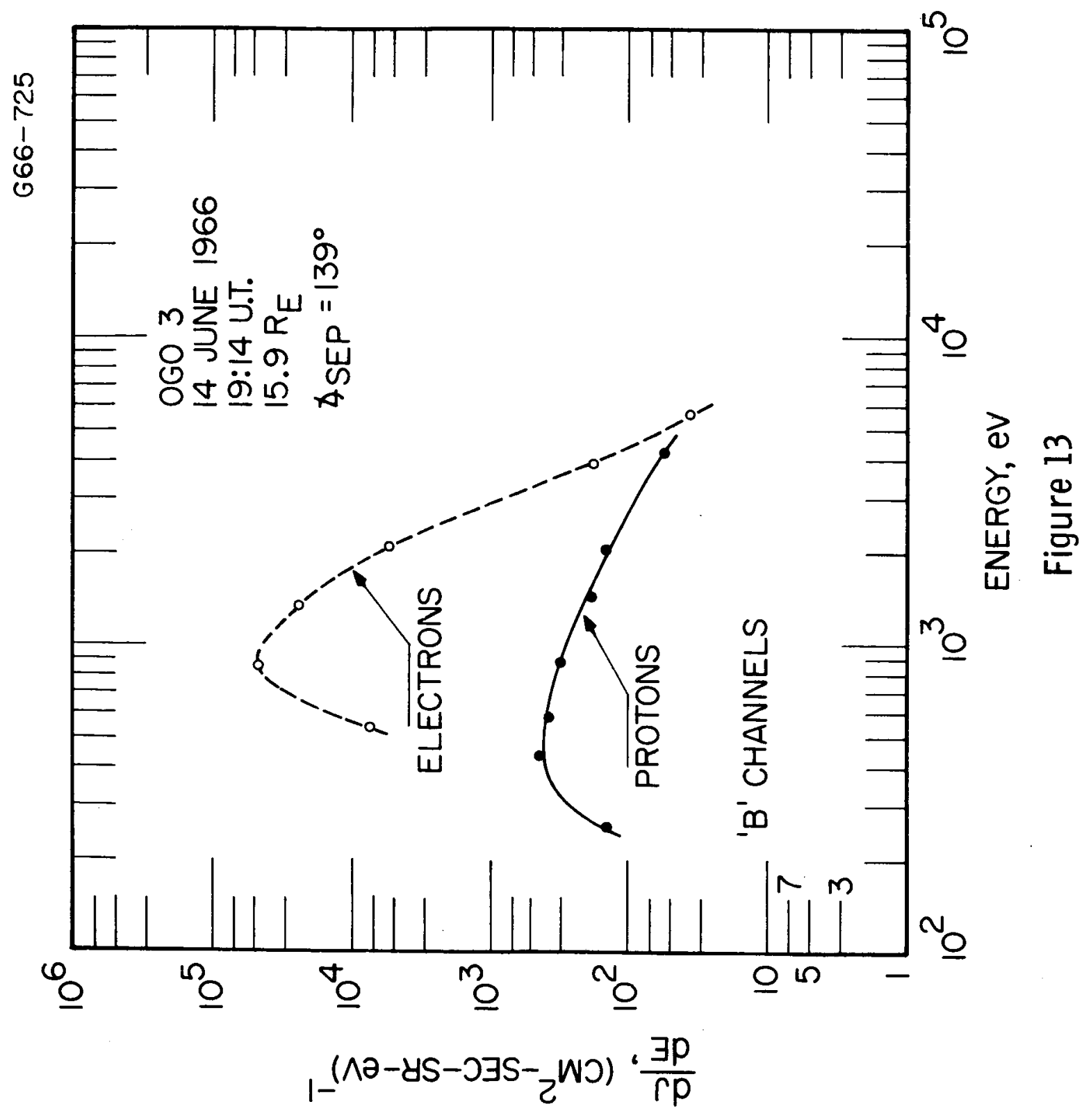




\section{DOCUMENT CONTROL DATA - R\&D}

\begin{tabular}{|c|c|c|}
\hline \multirow{2}{*}{\multicolumn{2}{|c|}{$\begin{array}{l}\text { 1. OaIGINATINGACTIVITY (Corporate author) } \\
\text { University of Iowa } \\
\text { Department of physics and Astronomy }\end{array}$}} & \multirow{2}{*}{$\begin{array}{l}\text { 2B. REPORT SECURITY CLASSIFICATION } \\
\text { UNCLASSIFIED } \\
\text { 26 GROUP }\end{array}$} \\
\hline & & \\
\hline \multicolumn{3}{|l|}{ 3. REPORT TITLE } \\
\hline \multicolumn{3}{|c|}{$\begin{array}{l}\text { Several Observations of Low-Energy Protons and Electrons in the Earth's } \\
\text { Magnetosphere with OGO } 3 \text {. }\end{array}$} \\
\hline \multicolumn{3}{|l|}{ 4. DESCRIPTIVE NOTES (Typo of report and Incluelve datoe) } \\
\hline \multicolumn{3}{|l|}{ Progress $\quad$ November 1966} \\
\hline \multicolumn{3}{|l|}{ Frank, L. A. } \\
\hline $\begin{array}{l}\text { 6. REPOAT DATE } \\
\text { NOVember } 1966\end{array}$ & $\begin{array}{l}\text { 7a. TOTALNO. OF PAGES } \\
5 I\end{array}$ & $\begin{array}{c}\text { 7b. NO. OF REFS } \\
\text { ly }\end{array}$ \\
\hline \multirow[t]{2}{*}{$\begin{array}{l}\text { 8. CONTRACT OR GRANT NO. NONR-1509(06) } \\
\text { b. PROJECT NO. }\end{array}$} & \multicolumn{2}{|c|}{$\begin{array}{l}\text { 9. ORIGINATOR'S REPORT NUMBER(S) } \\
\text { U. Of IOWa } 66-48\end{array}$} \\
\hline & \multicolumn{2}{|c|}{$\begin{array}{l}\text { 9b. OTHER REPORT NOSS) (A ny other numbore that may bo ceatened } \\
\text { this report) }\end{array}$} \\
\hline
\end{tabular}

\section{AVAILABILITY/LIMITA TION NOTICES}

Distribution of this document is unlimited.

\begin{tabular}{|l|l}
\hline 11. SUPPLEMENTARY NOTES & $\begin{array}{r}\text { 12. SPONSORING MILITARY ACTIVITY } \\
\text { Office of NaVaI Research }\end{array}$
\end{tabular}

13. Aestract Simultaneous observations of proton (190 eV $\leq \mathrm{E} \leq 48 \mathrm{keV}$ ) and electron $(170 \mathrm{eV} \leq \mathrm{E} \leq 46 \mathrm{keV})$ differential energy spectrums during segments of three outbound traversals of OGO 3 through the magnetosphere for the period $11-15$ June 1966 on L-shells 3.3 to 16 are presented. Proton intensities at $I=4$ on 15 June 1966 were $8 \times 10^{5}\left(\mathrm{~cm}^{2}-\mathrm{sec}-\mathrm{sr}\right)^{-1}(330 \leq \mathrm{E} \leq 530 \mathrm{eV}), \lesssim 1.5 \times 10^{6}\left(\mathrm{~cm}^{2}-\mathrm{sec}-\mathrm{sr}\right)^{-1}$ $(4.7 \leq \mathrm{E} \leq 7.6 \mathrm{keV})$ and $\lesssim 10^{6}\left(\mathrm{~cm}^{2}-\mathrm{sec}-\mathrm{sr}\right)^{-1}(16 \leq \mathrm{E} \leq 26 \mathrm{keV})$ and at $\mathrm{L}=7.5$ were $\leq 5 \times 10^{4}\left(\mathrm{~cm}^{2}-\mathrm{sec}-\mathrm{sr}\right)^{-1} \quad(330 \leq \mathrm{E} \leq 530 \mathrm{eV}), 4 \times 10^{6}\left(\mathrm{~cm}^{2}-\mathrm{sec}-\mathrm{sr}\right)^{-1} \quad(4.7 \leq \mathrm{E} \leq$ $7.6 \mathrm{keV})$ and $6 \times 10^{6}\left(\mathrm{~cm}^{2}-\mathrm{sec}-\mathrm{sr}\right)^{-1}(16 \leq \mathrm{E} \leq 26 \mathrm{keV})$ with local pitch angles $78^{\circ}\left( \pm 4^{\circ}\right)$ and at a geomagnetic latitude $23^{\circ}\left( \pm 1^{\circ}\right)$. Peak intensities of protons $(30 \leq \mathrm{E} \leq 48 \mathrm{keV}$ ) were observed at $\mathrm{L} \simeq 7.0$. A preliminary order-of-magnitude estimate of the total energy of trapped protons (190 eV $\leq \mathrm{E} \leq 48 \mathrm{keV}$ ) within the earth's magnetosphere is $5 \times 10^{21}$ ergs and the estimated contribution from this low-energy proton distribution to the quiet-time terrestrial ring current field at the earth's surface is $\sim-10 \%$. A transient, narrow peak of relatively high low-energy proton dil elcctron intensities within the energy range $300 \mathrm{eV}$ to 


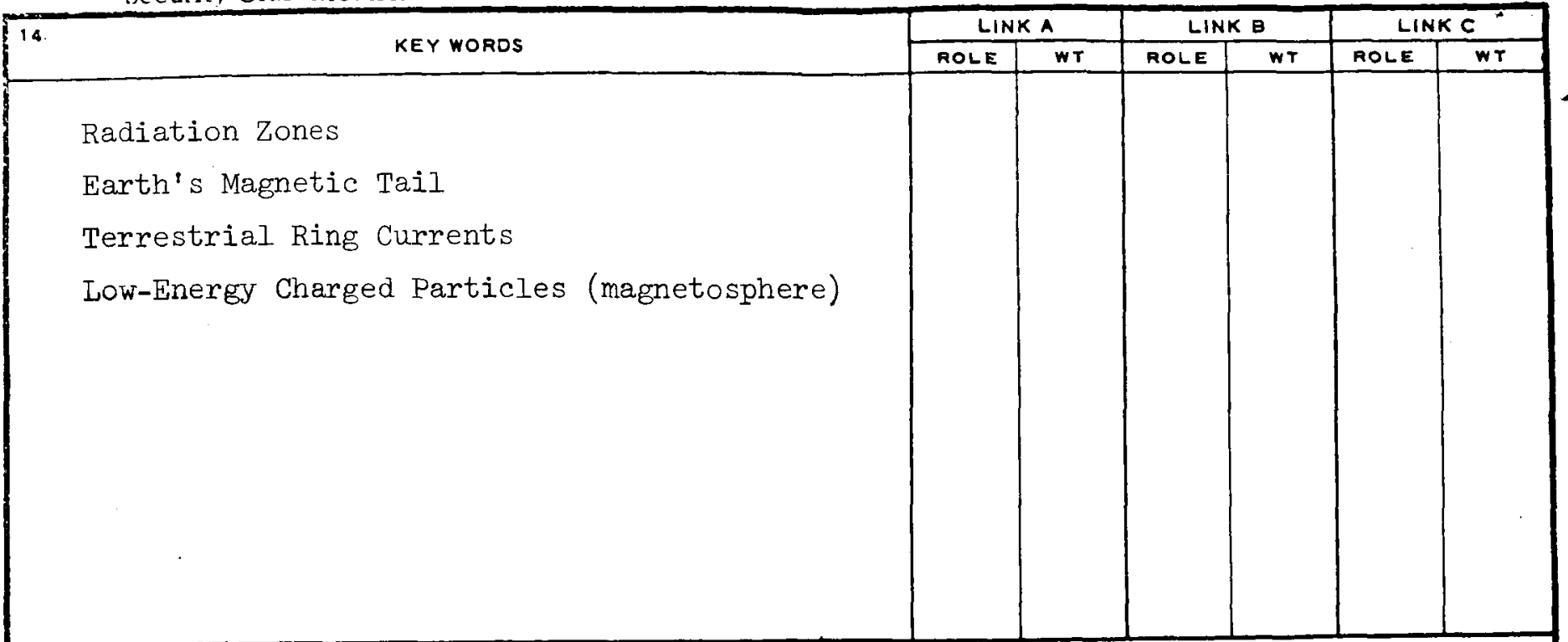

\section{INSTRUCTIONS}

1. ORIGINATING ACTIVITY: Enter the name and address of the contractor, subcontractor, grantee, Department of Defense activity or other organization (corporate author) issuing the report.

2a. REPORT SECURTY CLASSIFICATION: Enter the overall security classification of the report. Indicate whether "Restricted Data" is included Marking is to be in accordance with appropriate security regulations.

2b. GROUP: Automatic downgrading is specified in DoD Directive 5200.10 and Armed Forces Industrial Manual. Enter the group number. Also, when applicable, show that optional maikings have been used for Group 3 and Group 4 as authorized.

3. REPORT TITLE: Enter the complete report title in all capital letters. Titles in all cases should be urclassified. If a meaningful title cannot be selected without classification, show title classification in all capitals in parenthesis inmediately following the title.

4. DESCRIPTIVE NOTES: If appropriate, enter the type of report, e.g., interim, progress, summary, annual, or final. Give the inclusive dates when a specific reporting period is covered.

5. AUTHOR(S): Enter the name(s) of author(s) as shown on or in the report. Enter last name, first name, middle initial. If rilitary, show rank and branch of service. The name of the principal aithor is an absolute minimum requirement.

6. REPORT DATE: Enter the date of the report as day, month, year; or month, year. If more than one date appears on the report, use date of publication.

7a. TOTAL NUMBER OF PAGES: The total page count shouid follow normal pagination procedures, i. e., enter the number of pages containing information.

7b. NUMBER OF REFERENCES: Enter the total number of references cited in the report.

8 a. CONTRACT OR GRANT NUMBER: If appropriate, enter the applicable number of the contract or grant under which the report was written

$8 b, 8 c, \& 8 d$. PROJECT NUMBER: Enter the appropriate military department identification, such as project number, subproject number, system numbers, task number, etc.

9a. ORIGINATOR'S REPORT NUMBER(S): Enter the official report number by which the document will be ident ified and controlled by the originating activity. This number must be unique to this report.

9b. OTHER REPORT NUMBER(S): If the report has been assigned any other report numbers (either by the originator or by the sponsor), al so enter this number(s).

10. AVALABILITY/LIMITATION NOTICES: Enter any limitations on further dissemination of the report, other than those imposed by security classif̈cation, using standard statements such as:

(1) "Distribution of this document is unlimited."

(2) "Foreign announcement and dissemination of this report by DDC is not authorized."

(3) "U. S. Government agencies may obtain copies of this report directly from DDC. Other qual ified DDC users shall request through

(4) "U. S. military agencies may obtain copies of this report directly from DDC. Other qualified users shall request through

(5) "All distribution of this report is controlled Qualified DDC users shall request through "

If the report has been furnished to the Office of Technical Services, Department of Commerce, for sale to the public, indicate this fact and enter the price, if known.

11. SUPPLEMENTARY NOTES: Use for additional explanatory notes.

12. SPONSORING MILITARY ACTIVITY: Enter the name of the departmental project office or laboratory sponsoring (pay ing for) the research and development. Include address.

13. ABSTRACT: Enter an abstract giving a brief and factual summary of the document indicative of the report, even though it may also appear elsewhere in the body of the technical report. If additional space is required, a continuation sheet shall be attached.

It is highly desirable that the abstract of classified reports be unclassified. Each paragraph of the abstract shall end with an indication of the military security classification of the information in the paragraph, represented as $(T S),(S),(C)$, or (U)

There is no limitation on the length of the abstract. However, the suggested length is from 150 to 225 words.

14. KEY WORDS: Key words are technically meaningful terms or short phrases that characterize a report and may be used as index entries for cataloging the report. Key words must be selected so that no security classification is required. Identifiers, such as equipment model designation, trade name, military project code name, geographic location, may be used as key words but will be followed by an indication of technical context. The assignment of links, rales, and weights is optional. 
$2 \mathrm{keV}$ at $\mathrm{I} \simeq 4$ with width $\Delta \mathrm{I} \sim 1$ is also observed. Typical characteristics of proton and electron intensity 'spikes' at peak intensities in the late evening sector of the earth's magnetic tail are (a) approximately equal proton (190 eV $\leq \mathrm{E} \leq 48 \mathrm{keV}$ ) and electron (170 eV $\leq \mathrm{E} \leq 46 \mathrm{keV}$ ) energy densities, $\sim 10^{-9} \overline{\mathrm{erg}}(\mathrm{cm})^{-3}$ each, (b) approximately equal proton and electron densities over the above energy range, $\sim 1(\mathrm{~cm})^{-3}$ sach, and (c) largely dissimilar differential energy spectrums, proton spectrums with intensity peaks noncoincident in energy with those of the electron intensity peaks and significantly broader (harder) in the high-energy tail ( $\mathrm{E} \approx 3 \mathrm{keV}$ ) than the relatively steep (soft) electron spectrums in this energy range. 